\title{
Optimal monetary policy with the risk-taking channel
}

Angela Abbate, Dominik Thaler

SNB Working Papers

9/2021 


\section{DISCLAIMER}

The views expressed in this paper are those of the author(s) and do not necessarily represent those of the Swiss National Bank. Working Papers describe research in progress. Their aim is to elicit comments and to further debate.

\section{COPYRIGHT $\odot$}

The Swiss National Bank (SNB) respects all third-party rights, in particular rights relating to works protected by copyright (information or data, wordings and depictions, to the extent that these are of an individual character).

SNB publications containing a reference to a copyright (@) Swiss National Bank/SNB, Zurich/year, or similar) may, under copyright law, only be used (reproduced, used via the internet, etc.) for non-commercial purposes and provided that the source is mentioned. Their use for commercial purposes is only permitted with the prior express consent of the SNB.

General information and data published without reference to a copyright may be used without mentioning the source. To the extent that the information and data clearly derive from outside sources, the users of such information and data are obliged to respect any existing copyrights and to obtain the right of use from the relevant outside source themselves.

\section{LIMITATION OF LIABILITY}

The SNB accepts no responsibility for any information it provides. Under no circumstances will it accept any liability for losses or damage which may result from the use of such information. This limitation of liability applies, in particular, to the topicality, accuracy, validity and availability of the information.

ISSN 1660-7716 (printed version)

ISSN 1660-7724 (online version)

(C) 2021 by Swiss National Bank, Börsenstrasse 15,

P.O. Box, $\mathrm{CH}-8022$ Zurich 


\title{
Optimal Monetary Policy with the Risk-Taking Channel*
}

\author{
Angela Abbate,$^{\dagger}$ Dominik Thaler ${ }^{\ddagger}$
}

April 16, 2021

\begin{abstract}
Empirical research suggests that lower interest rates induce banks to take higher risks. We assess analytically what this risk-taking channel implies for optimal monetary policy in a tractable New Keynesian model. We show that this channel creates a motive for the planner to stabilize the real rate. This objective conflicts with the standard inflation stabilization objective. Optimal policy thus tolerates more inflation volatility. An inertial Taylor-type reaction function becomes optimal. We then quantify the significance of the risk-taking channel for monetary policy in an estimated medium-scale extension of the model. Ignoring the channel when designing policy entails non-negligible welfare costs $(0.7 \%$ lifetime consumption equivalent).
\end{abstract}

Keywords: Risk-taking channel, Optimal monetary policy

JEL classification: E44, E52

${ }^{*}$ The views, opinions, findings, and conclusions or recommendations expressed in this paper are strictly those of the author(s). They do not necessarily reflect the views of the Swiss National Bank (SNB) or the Banco de España (BdE). The SNB and the BdE take no responsibility for any errors or omissions in, or for the correctness of, the information contained in this paper. We thank Harris Dellas, Beatriz Gonzalez, Thomas Lejeune, Galo Nuño, Evi Pappa, Federico Ravenna, Tiziano Ropele and participants in a seminar at the Bank of Spain, the 23rd Central Bank Macro Modeling Workshop and the 2020 ESCB research cluster 1 conference for their comments.

${ }^{\dagger}$ Swiss National Bank, Angela.Abbate@snb.ch

${ }^{\ddagger}$ Bank of Spain, Dominik.Thaler@eui.eu 


\section{Introduction}

The risk-taking channel of monetary policy - the mechanism by which lower interest rates encourage banks to take on additional risk - is a well-established empirical regularity. Studies have shown that this channel was active both before and after the 2008 financial crisis. ${ }^{1}$ Despite policymakers' awareness of the risk-taking channel, its normative implications for monetary policy remain to be determined. ${ }^{2}$ Should central banks consider their influence on bank risk taking when setting their policy rates, and if so, how?

We explore these questions in two steps. First, we embed a tractable model of bank risk taking into the textbook New Keynesian model (NKM), and analytically characterize optimal monetary policy under a linear-quadratic approximation. Second, we embed the same model of the risk-taking channel into a larger New Keynesian DSGE model estimated using US data, and we use it to explore the quantitative importance of the risk-taking channel for optimal monetary policy. We show analytically that the risk-taking channel provides an incentive for the central bank to minimize the volatility of the real interest rate, conflicting with the standard New Keynesian policy prescription to minimize inflation volatility. Hence, the risk-taking channel introduces a new trade-off for the policy maker. We find this new trade-off to be quantitatively significant in the large model: Ignoring the risk-taking channel when designing optimal monetary policy entails welfare costs of approximately $0.7 \%$ of lifetime consumption equivalent.

To derive the analytical conclusions, we set up a simple New Keynesian model with financial intermediation and a bank risk-taking channel. Firms must borrow in advance to finance production, as in Ravenna and Walsh (2006). Firms' technologies are risky and differ in their risk-return characteristics. Banks provide the necessary external financing to firms by funding themselves through equity and deposits, and they choose the riskiness of the firm in which they invest. As in Dell'Ariccia et al. (2014), frictions in the banking system - limited liability, the unobservability of risk taking, and an equity premium - cause a risk shifting problem. Banks choose to lend to excessively risky firms, in the sense that a reduction in risk would increase

\footnotetext{
${ }^{1}$ E.g. Maddaloni and Peydro (2011), Buch et al. (2014), Ioannidou et al. (2014), Jimenez et al. (2014), Heider et al. (2019), Bubeck et al. (2020).

${ }^{2}$ For example, ECB board member Mersch (2020) remarked that "monetary accommodation incentivizes financial firms to increase risk taking", while FOMC meeting participants discussed the possibility of "adjusting the stance of monetary policy to mitigate financial stability risks", particularly when macroprudential tools were likely to be ineffective (FOMC, 2020).
} 
the expected social return on their investment. The level of the real interest rate influences the degree of banks' risk taking: Lower real interest rates induce banks to choose even riskier investments, thus giving rise to the risk-taking channel of monetary policy.

Since risk taking comes at the cost of lower expected return on investment, the central bank might wish to reduce risk taking by increasing the average level of real interest rates. However, due to long-run neutrality of monetary policy, the central bank cannot control the long run level of the real interest rate. Nevertheless, this does not render the risk-taking channel irrelevant for monetary policy. As we show analytically, the average efficiency of banks' investments decreases not only in the level, but also in the volatility of the real interest rate. The latter can be controlled by the central bank. Thus the risk-taking channel translates into an motive for the central bank to stabilize the real interest rate around its policy-independent average level.

The model remains highly tractable and, in linearized form, boils down to a modification of the textbook three-equation NKM, which allows us to characterize optimal monetary policy analytically using a linear quadratic approximation and to derive the impact of the risk-taking channel on optimal policy. We derive four key results. First, we show that welfare depends not only on output gap and inflation volatility, as in the standard NKM, but also on the volatility of the real interest rate. Second, we find that the inclusion of the risk-taking channel implies less real interest rate volatility, but greater inflation volatility under optimal policy. Third, the presence of the risk-taking channel decreases the optimal response to inflation in the central bank's Taylor rule. These last two results hold true regardless of whether we consider optimal policy under discretion or optimal simple rules under commitment. Fourth, we derive an implicit instrument rule that implements fully Ramsey-optimal policy under commitment, and find that the risk-taking channel requires inertia in the policy rate. The risk-taking channel thus provides a novel explanation for interest rate inertia, which is routinely built into Taylor rules in models and typically observed empirically.

Having explored the risk-taking channel analytically in a stylized model, we then turn to the question of whether this channel is also quantitatively relevant for optimal monetary policy. To address this question, we use the medium scale DSGE model of Abbate and Thaler (2019). This model combines the same banking-sector model described above with an otherwise standard medium scale New-Keynesian 
model à la Smets and Wouters (2007). This model provides a reasonable description of macro-dynamics and is thus a better laboratory for quantitative analysis. In fact, Abbate and Thaler (2019) estimate the model using US data and show that the inclusion of the risk-taking channel improves the fit of the model for macroeconomic time series, generates a path of risk taking that matches survey evidence on the riskiness of newly issued loans, and gives rise to procyclical bank leverage, as documented by Adrian and Shin (2014).

We employ this model to numerically determine optimal policy under simple rules. We derive four results that confirm and quantify the four theoretical results mentioned above. First, the central bank accepts approximately 50\% more inflation volatility than in the absence of the risk-taking channel. Second, the optimal Taylor rule features a significantly lower response to inflation and, third, an autoregressive coefficient of approximately 1 when the risk-taking channel is active. Fourth and most importantly, the welfare costs of considering the risk-taking channel when designing optimal monetary policy are significant, and amount to around $0.7 \%$ of lifetime consumption equivalent. The risk-taking channel thus has the potential to affect optimal policy significantly. This contrasts findings in the literature that other types of financial frictions do not affect optimal monetary policy significantly (e.g. Bernanke and Gertler, 2001 or De Fiore and Tristani, 2013).

Our model builds on an extensive literature documenting the risk-taking channel empirically, including Maddaloni and Peydro (2011), Buch et al. (2014), Ioannidou et al. (2014), Jimenez et al. (2014), Bubeck et al. (2020) and Heider et al. (2019). They all find that low rates increase the riskiness of banks' new investments. The second and third paper add an important qualification to the risk-taking channel by showing that banks do not offset higher risk with a sufficiently large increase in the risk premium. Risk taking is thus inefficient, as in our model.

The main contribution of this paper is twofold. First, we contribute to the theoretical macro literature on the risk-taking channel. This literature has so far taken a largely positive approach and described different versions of the risk-taking channel. Many models focus on the risks generated by the banks' leverage choice on the liabilities side of their balance sheets. Some link greater leverage to a stronger financial accelerator (e.g. Gertler et al., 2012 and de Groot, 2014), while others link it to a larger incidence of bank runs (Angeloni and Faia, 2013 and Angeloni et al., 2015). Closer to the empirical literature cited above, other authors focus on the riskiness of banks' investments, that is, on risk taking on the asset side of their balance sheets. 
Christensen et al. (2011) and Collard et al. (2017) are two examples, but in their models market discipline or regulation always ensures that risk taking is efficient in equilibrium, so there is no important role for monetary policy. In contrast, our companion paper Abbate and Thaler (2019) and Afanasyeva and Guentner (2020) explore the interactions of monetary policy and banks' asset risk taking in a medium scale DSGE model from a positive point of view.

The first contribution of this paper is therefore to add normative conclusions for monetary policy to this largely positive literature. ${ }^{3}$ In doing so, our paper is related to Martinez-Miera and Repullo (2019), who provide a simple two period macromodel in which banks' asset risk taking is modeled and affected by monetary policy in a very similar way. Since risk taking is excessive from a social point of view, the authors argue that this mechanism constitutes a motive for the central bank to increase the real interest rate through monetary policy. Because we consider monetary policy in the long run under rational expectations, our message contrasts with theirs. We argue that monetary policy cannot systematically raise the real interest rate due to monetary neutrality, which is a central tenet of New Keynesian theory. However, monetary policy can still affect risk taking by influencing the volatility of the real interest rate. ${ }^{4}$

The second contribution is to the normative literature on monetary policy inertia. While the inertial nature of policy rates is well documented empirically and inertial Taylor rules are standard in monetary models, it is theoretically not straightforward that such inertia is optimal form a planner's point of view. By showing that the risk-taking channel adds an interest rate variation term to the welfare function and leads to an inertial rule under Ramsey policy, we provide a novel theory that can explain inertial interest rate policy. In doing so, we complement other explanations for why interest rate volatility matters for welfare, such as the zero lower bound or transactions frictions in Woodford (2003). ${ }^{5}$

The paper proceeds as follows: In section 2 we set up a simple NKM with the risk-

\footnotetext{
${ }^{3}$ Of course, the risk-taking channel also has important normative implications for regulatory policy, from which we abstract for simplicity. We view this choice as a shortcut to model the arguably realistic fact that regulation might not be $100 \%$ effective at muting the risk-taking channel in practice - otherwise the channel should not be in the data.

${ }^{4}$ We conjecture that our intuition might also apply to Martinez-Miera and Repullo (2019) in the long run. Since the welfare function is concave in the real rate, a mean preserving increase in the volatility of the real rate is detrimental to average welfare.

${ }^{5}$ Note that while in our case it is the real interest rate, not the nominal one, that appears in the welfare function, the effects are similar.
} 
taking channel, which we then use in section 3 to explore optimal policy analytically. In section 4 we briefly discuss the medium scale model, which we then use to analyze the quantitative importance for optimal policy numerically. Section 5 concludes.

\section{A simple New Keynesian model of the bank risk- taking channel}

In this section, we set up a simple New Keynesian model with financial intermediation and a bank risk-taking channel. We build on Ravenna and Walsh's (2006) model of the cost channel, where firms need to borrow in advance to finance production. While we are not interested in the cost channel per se, it represents a tractable and parsimonious way to introduce intermediation into the textbook three-equation New Keynesian model without introducing capital. ${ }^{6}$ We extend this basic model of intermediation to introduce the risk-taking channel as in Abbate and Thaler (2019), who build on Dell'Ariccia et al. (2014). Firm's production technology is risky and banks, who finance firms, can choose the riskiness of the firm they lend to.

The simplicity of the model has two advantages: First, we can cleanly demonstrate how bank risk taking alters the otherwise standard set of equations of a basic New Keynesian model. Second, we can derive an analytical approximation of the social welfare function, as well as optimal monetary policy rules. Finally, while simple, the model replicates two key stylised facts about the asset risk-taking channel established in the empirical literature. First, that lower interest rates induce banks to make riskier loans (e.g. Jimenez et al., 2014). Second, that the increase in risk exposure is not offset by an increase in risk premia (Buch et al., 2014 and Ioannidou et al., 2014), i.e. that this additional risk is inefficient.

The model economy has eight types of agents: Households, input good producers, intermediate goods producers, final good producers, equity and deposit funds, private banks, and the central bank. We discuss these agents in turn.

\section{$2.1 \quad$ Households}

Households choose consumption $C_{t}$, working hours $N_{t}$, cash holdings $M_{t}$ and shares in the equity and deposit funds $E_{t}$ and $D_{t}$ in order to maximize their discounted

\footnotetext{
${ }^{6}$ Introducing capital makes the optimal policy problem analytically intractable. In the numerical analysis in section 4 we introduce intermediation through capital rather than the cost channel.
} 
lifetime utility:

$$
U_{t}=\mathbb{E}_{t} \sum_{i=0}^{\infty} \beta^{i}\left[\frac{C_{t}^{1-\sigma}}{1-\sigma}-\frac{N_{t}^{1+\varphi}}{1+\varphi}\right]
$$

Timing is as follows: Households enter period $t$ with nominal money holdings $M_{t-1}$. They then receive wage income $W_{t} N_{t}$ in cash as well as a lump-sum cash injection $X_{t}$ from the central bank. They then use this cash to investment into equity and deposit funds $D_{t}$ and $E_{t}$, and to purchase the consumption good $C_{t}$, which has to be paid in advance. Hence, consumption is subject to the following cash-in-advance (CIA) constraint:

$$
P_{t} C_{t} \leq M_{t-1}+W_{t} N_{t}-D_{t}-E_{t}+X_{t}
$$

At the end of the period, households work and consume the previously chosen quantities $N_{t}$ and $C_{t}$. Furthermore, the household receives payments from the equity and deposit funds remunerated at the safe nominal (gross) rate $R_{t}^{e}$ and $R_{t}^{d}$, as well as any profit income $\Pi_{t}$ from firms and the two funds. Hence, cash holdings $M_{t}$ at the end of the period are:

$$
M_{t}=M_{t-1}+W_{t} N_{t}-D_{t}-P_{t} C_{t}+R_{t}^{d} D_{t}+R_{t}^{e} E_{t}+\Pi_{t}+X_{t}
$$

Utility maximization implies that the two safe interest rates are the same, so that we can simply refer to the safe rate as $R_{t}$ :

$$
R_{t}^{e}=R_{t}^{d} \equiv R_{t}
$$

Utility maximization also yields the usual labor supply condition and the Euler equation:

$$
\begin{aligned}
\frac{N_{t}^{\varphi}}{C_{t}^{\sigma}} & =\frac{W_{t}}{P_{t}} \\
C_{t}^{-\sigma} & =\beta \mathbb{E}_{t}\left[C_{t+1}^{-\sigma} \frac{R_{t}}{\pi_{t+1}}\right],
\end{aligned}
$$

Furthermore, the CIA constraint (1) must hold with equality in any equilibrium with positive nominal rates. 


\subsection{Input good producers}

There exists a continuum of ex-ante identical input good producers indexed by $m$, who hire labor $N^{m}$ to produce the input good $z_{t}^{m}$ using a risky production technology, which has constant returns to scale (CRS) with respect to labor. Each input producer has access to a continuum of technologies with different risk-return characteristics indexed by $q^{m} \in[0,1]$. Given a certain technology $q_{t}^{m}$, the output of producer $m$ is:

$$
Z_{t}^{m}= \begin{cases}\left(\omega_{1}-\frac{\omega_{2}}{2} q_{t}^{m}\right) N_{t}^{m} & \text { with probablity } q_{t}^{m} \\ 0 & \text { else }\end{cases}
$$

Input producers need to pre-pay the wage bill $W_{t} N_{t}^{m}$ at the beginning of the period, but only produce at the end of the period. They therefore need to borrow from the bank in order to finance the wage bill. They promise to repay the loan after production at the gross nominal loan rate $r_{l, t}$ and let the bank choose the riskiness of their technology $q_{t} \cdot{ }^{7}$ If the production process is successful, producers sell the input good at price $P_{i n, t}$ and repay the loan. If the production process is not successful, the producers default.

Input producers choose the scale of production that maximises their profits. Price taking and the linearity of the production technology in $N_{t}$ imply that they pass on all their revenues to the bank and make zero profits. Hence, the nominal price of the input good is equal to:

$$
P_{i n, t}=r_{l, t} W_{t} /\left(\omega_{1}-\frac{\omega_{2}}{2} q_{t}^{m}\right)
$$

Given that the producers' output is uncorrelated, and that in equilibrium all producers use the same technology $q_{t}$, the quantity of input goods produced in equilibrium is given by:

$$
Z_{t}=\underbrace{q_{t}\left(\omega_{1}-\frac{\omega_{2}}{2} q_{t}\right)}_{\mathrm{f}\left(q_{t}\right)} N_{t}
$$

where $Z_{t} \equiv \int_{m=0}^{1} Z^{m} d m, N_{t} \equiv \int_{m=0}^{1} N^{m} d m$, and where $\mathrm{f}\left(q_{t}\right)$ denotes the expected productivity of input good producers.

\footnotetext{
${ }^{7}$ Alternatively, one can assume that $q_{m}$ is a fixed characteristic of a producer, but that there exists a continuum of producers for each $q_{m} \in[0,1]$.
} 


\subsection{Final and intermediate good producers}

Final and intermediate good producers are standard and hence discussed only briefly. A representative final good producer aggregates intermediate good varieties $Y^{i}$ to produce the final consumption good $Y$ according to the CES aggregator:

$$
Y_{t}=\left[\int_{0}^{1}\left(Y^{i}\right)^{\left(\theta_{t}-1\right) / \theta_{t}} d i\right]^{\theta_{t} /\left(\theta_{t}-1\right)}
$$

There is a continuum of intermediate good producers indexed by $i$ who produce differentiated intermediate goods under monopolistic competition and Calvo pricing. Their CRS technology is given by $Y^{i}=A_{t} Z_{t}^{i}$, i.e. they linearly transform input goods into intermediate varieties, where $A_{t}$ is total factor productivity. They purchase input goods at price $P_{i n, t}$ and receive a proportional subsidy $\tau_{t}$ on their purchases. This subsidy is financed by lump sum taxes on the household and plays a similar role as the labor subsidy often used in the textbook NKM. Hence, their nominal marginal cost is given by $M C_{t}=\frac{P_{i n, t}\left(1-\tau_{t}\right)}{A_{t}}$, which using (6), can be rewritten as:

$$
M C_{t}=\frac{W_{t} r_{l, t} q_{t}\left(1-\tau_{t}\right)}{A_{t} q_{t}\left(\omega_{1}-\frac{\omega_{2}}{2} q_{t}^{m}\right)}
$$

Note that the above marginal cost definition differs from the standard one in the basic New Keynesian model (e.g. Galí, 2015) in two ways. First, due to the presence of different risky production technologies: Input good production is risky at firm level, but one unit of labor is transformed into $\mathrm{f}\left(q_{t}\right)=q_{t}\left(\omega_{1}-\frac{\omega_{2}}{2} q_{t}^{m}\right)$ units of input goods on average across all input goods producers. The higher the productivity of inputs good producers $\mathrm{f}\left(q_{t}\right)$, the lower the marginal costs of intermediate firms. Second, due to the presence of the cost-channel as in Ravenna and Walsh (2006): Since input producers have to pre-finance their wage bill, their marginal costs are given by the wage bill multiplied by expected gross interest payments on the wage bill $q_{t} r_{l, t}$. Since we are not interested in the cost channel per se, we assume that the government sets the subsidy $\tau_{t}$ such that the cost channel is muted $\tau_{t}=1-\frac{1}{q_{t} r_{l, t}} .8$ This subsidy is not relevant for the derivation of the welfare function in section

\footnotetext{
${ }^{8}$ The cost channel only serves as a convenient device to introduce intermediation into the 3equation NKM without capital. The implications of the cost channel for optimal policy are discussed in detail in Ravenna and Walsh (2006). In the medium scale model which we explore numerically in the last section, we do not need to rely on the cost channel since the presence of capital allows to introduce intermediation in a more straightforward way.
} 
3.1, but it simplifies the Phillips curve and, as a result, the derivation of optimal monetary policy. ${ }^{9}$ Marginal costs are thus:

$$
M C_{t}=\frac{W_{t}}{A_{t} q_{t}\left(\omega_{1}-\frac{\omega_{2}}{2} q_{t}^{m}\right)}
$$

Marginal costs now differ from the standard definition only due to the risk-taking channel. We will discuss the implication of this difference later.

Price setting is standard. Every period, each intermediate good producer can reset its price $P_{t}^{i}$ with probability $1-\omega$. The price is set to maximize expected discounted profits, using the households stochastic discount factor and taking the demand function for their variety as given. This leads to the standard dynamics of aggregate prices and price dispersion reported in Appendix A.

\subsection{Equity and deposit funds}

As we explain in the next subsection, there is a continuum of banks indexed by $b$ which fund loans through deposits $D_{t}^{b}$ and equity $E_{t}^{b}$ at the beginning of the period. Each bank is subject to a binary idiosyncratic shock, which makes a bank fail with probability $1-q_{t}$. If the bank fails, both equity holders and depositors loose their investment. If the bank does not fail, bank deposits and equity pay the gross nominal deposit and equity rates $r_{d}^{b}$ and $r_{e}^{b}$ at the end of the period. The deposit and equity funds hold the deposits and equity of all banks, thus diversifying away any idiosyncratic risk. They are financed by fund shares purchased by the household such that $D_{t}=\int_{0}^{1} D_{t}^{b} d b$ and $E_{t}=\int_{0}^{1} E_{t}^{b} d b$. Note that the funds merely serve as modeling devices to simplify the exposition. ${ }^{10}$

The deposit fund is a frictionless pass-on vehicle. It invests its funds into all banks, represents the depositors' interests perfectly and returns the nominal deposit fund rate $R_{d, t}$, which is simply the average return on deposits:

$$
R_{d, t}=q_{t} r_{d, t}
$$

As a simple way to introduce an equity premium, we assume the equity fund manager

\footnotetext{
${ }^{9}$ We will not impose this subsidy in the large model in section 4 , and we have verified numerically that it would not affect the results reported there significantly.

${ }^{10}$ Equivalently, we could assume that the household perfectly diversifies its deposits and equity across banks, or that there is perfect risk sharing among a continuum of households, each interacting with one bank.
} 
is paid a (real) premium $\xi$ per unit of funds under management to incentivize him to act in the best interest of equity providers. This premium is rebated to the household in a lump-sum fashion as part of his profit income. ${ }^{11}$ The nominal return on the equity fund is hence given by the average return on bank equity minus the premium:

$$
R_{e, t}=q_{t} r_{e, t}-\xi \mathbb{E}_{t} \pi_{t+1}
$$

Since both funds are perfectly diversified, the returns of both funds are risk free. Hence, the households' FOCs imply that the return on fund shares are equated $R_{e, t}=R_{d, t} \equiv R_{t}$. Nevertheless, the costs of deposit and equity financing for banks differ from each other due to the equity premium $\xi$. To see this, combine this equality with equations (9) and (10) to find that:

$$
q_{t} \frac{r_{e, t}}{\mathbb{E}_{t} \pi_{t+1}}=q_{t} \frac{r_{d, t}}{\mathbb{E}_{t} \pi_{t+1}}+\xi
$$

This simple way of modeling the equity premium could also be reinterpreted as transaction costs of equity or a convenience yield of deposits. ${ }^{12}$ The equity premium invalidates the Modigliani-Miller irrelevance principle and, as we will see, plays an important role in delivering the risk-taking channel.

\subsection{Banks}

Banks finance themselves through deposits and equity, and invest these funds into risky assets. In particular, banks choose the scale of their balance sheet, their capital structure and the riskiness of their assets, taking interest rates as given. We show in this section that the bank risk choice has implications for the allocative efficiency of the economy, and therefore bears implications for monetary policy. The modeling of the banks follows Abbate and Thaler (2019), who build on Dell'Ariccia et al. (2014), and involves three key assumptions: (i) Unobservability of the bank's risk

\footnotetext{
${ }^{11}$ This equity premium can be explained by a simple agency problem. Assume the equity fund's manager faces two possibilities. Either he behaves diligently, investing funds $E_{t}$ into banks at the beginning of the period, paying back the return of this investment at the end of the period. Or he absconds with the cash at the beginning of the period, consuming a fraction $\xi$ in the next period, while the rest is lost. To prevent the latter, equity providers promise to pay him a premium $p_{t}$ at the end of the period, conditional on not absconding. The minimal premium that induces diligent behavior is $p_{t}=\xi_{t} \mathbb{E}_{t} \pi_{t+1}$.

${ }^{12}$ This assumption about equity is common, e.g. Allen et al. (2011) or Hellmann et al. (2000). Gorton and Winton (2017) provides a microfoundation where the equity premium arises from a liquidity motive.
} 
choice and (ii) limited liability of the bank, which give rise to an agency problem between depositors and equity providers, and (iii) the cost advantage of deposits over equity introduced in the previous subsection.

There is a continuum of ex-ante identical competitive banks (for convenience we omit the bank's index $b$ in this subsection). Banks live for one period. At the beginning of the period, each bank chooses how much deposits $D_{t}$ and equity $E_{t}$ to raise from the respective funds, and lends these resources to one particular input good producer at a promised (gross) rate $r_{l, t}$. When lending to an input producer, the bank chooses the risk characteristic $q_{t}$ of the technology employed by the producer. ${ }^{13}$ While the bank selects the level of risk, depositors cannot observe this risk choice. Hence deposit contracts cannot be made contingent upon the bank's risk choice, and the bank cannot credibly commit to a certain risk choice either. At the end of the period, the bank's loan is due. Since each bank invests into only one input producer, the return on the bank's assets is risky. If the input good producer is successful, which happens with probability $q_{t}$, the bank receives $r_{l, t}\left(E_{t}+D_{t}\right)$. In that case, the bank repays its deposits and equity at the promised nominal (gross) rates $r_{d, t}$ and $r_{e, t}$. With probability $1-q_{t}$, the production fails, and the loan is worthless. In this case, limited liability protects equity providers from depositors' claims such that both depositors and equity providers receive nothing.

It is convenient to understand the bank's problem as a two-stage problem. At stage 1, the bank chooses the scale of its balance sheet and the capital structure. At stage 2 , once the balance sheet has been determined and the deposit rate has been fixed, the bank chooses the risk level $q_{t}$. At each stage, the bank maximizes the expected value of its profits net of the user cost of equity - excess profits for short. The bank's objective function is hence given by:

$$
q_{t}\left\{r_{l, t}-r_{d, t} \frac{D_{t}}{E_{t}+D_{t}}-r_{e, t} \frac{E_{t}}{E_{t}+D_{t}}\right\}\left(E_{t}+D_{t}\right)
$$

When choosing the riskiness of its investment $q_{t}$, the bank understands the risk return trade-off implied by the capital producers' optimality condition (6). We can hence substitute $r_{l, t}$ in the above expression. Furthermore, define the equity ratio as $k_{t} \equiv \frac{E_{t}}{E_{t}+D_{t}}$ and the total balance sheet size by $o_{t} \equiv D_{t}+E_{t}$ and divide everything by expected inflation to obtain:

\footnotetext{
${ }^{13}$ The choice of $q_{t}$ may be interpreted both as lending to borrowers of different risk levels, or as the adjustment of lending terms (collateral, covenants etc.) to the same borrower so as to make repayment more likely. Also see FN 7.
} 


$$
\mathbb{E}_{t}\left[\frac{1}{\pi_{t+1}}\left\{\left(\omega_{1} q_{t}-\frac{\omega_{2}}{2} q_{t}^{2}\right) \frac{P_{i n, t}}{W_{t}}-q_{t} r_{d, t}\left(1-k_{t}\right)-q_{t} r_{e, t} k_{t}\right\} o_{t}\right] .
$$

To simplify notation, we rewrite the objective function in real variables using the following definitions: $\tilde{r}_{l, t}^{r}=\mathbb{E}_{t}\left[\frac{1}{\pi_{t+1}} \frac{P_{i n, t}}{W_{t}}\right], r_{d, t}^{r}=\mathbb{E}_{t}\left[r_{d, t} / \pi_{t+1}\right], r_{e, t}^{r}=\mathbb{E}_{t}\left[r_{e, t} / \pi_{t+1}\right], R_{t}^{r}=$ $\mathbb{E}_{t}\left[R_{t} / \pi_{t+1}\right]$. The objective function can be reexpressed as:

$$
\left\{\left(\omega_{1} q_{t}-\frac{\omega_{2}}{2} q_{t}^{2}\right) \tilde{r}_{l, t}^{r}-q_{t} r_{d, t}^{r}\left(1-k_{t}\right)-q_{t} r_{e, t}^{r} k_{t}\right\} o_{t} .
$$

Now we solve the bank's problem recursively.

At the second stage, the bank has already raised $E_{t}+D_{t}$ funds and now needs to choose the riskiness of its investment $q_{t}$. As already mentioned, we assume that the bank cannot write contracts conditional on $q_{t}$ with the depositors at stage one. Therefore, at the second stage the bank takes the deposit rate as given. Furthermore, since the capital structure is already determined, maximizing expected excess profits coincides with maximizing the expected total profit of the equity holders. The second stage problem is thus:

$$
\max _{q_{t}}\left(\omega_{1} q_{t}-\frac{\omega_{2}}{2} q_{t}^{2}\right) \tilde{r}_{l, t}^{r}-q_{t} r_{d, t}^{r}\left(1-k_{t}\right)
$$

The FOC reads:

$$
q_{t}=\frac{\omega_{1} \tilde{r}_{l, t}^{r}-r_{d, t}^{r}\left(1-k_{t}\right)}{\omega_{2} \tilde{r}_{l, t}^{r}} .
$$

At the first stage, the bank chooses the capital structure $k_{t}$ and the balance sheet size $o_{t}$ to maximize expected excess profits, subject to the participation constraints (i.e. the funding supply schedules) for depositors and equity providers. Since agents have rational expectations, everyone correctly infers the level of risk $q_{t}$ that will be chosen by the bank at the second stage as a function of $k_{t}, r_{d, t}^{r}$ and $\tilde{r}_{l, t}^{r}$. The first stage problem is thus

$$
\begin{aligned}
& \max _{k_{t}, o_{t}, q_{t}, r_{d, t}^{r}, r_{e, t}^{r}} o_{t}\left\{\tilde{r}_{l, t}^{r}\left(q_{t} \omega_{1}-\frac{\omega_{2}}{2} q_{t}^{2}\right)-q_{t} r_{d, t}^{r}\left(1-k_{t}\right)-q_{t} r_{e, t}^{r}\left(1-k_{t}\right)\right\} \\
& \text { s.t. } r_{d, t}^{r}=\frac{R_{t}^{r}}{q_{t}} \text { and } r_{e, t}^{r}=\frac{R_{t}^{r}+\xi}{q_{t}} \text { and } q_{t}=\frac{\omega_{1} \tilde{r}_{l, t}^{r}-r_{d, t}^{r}\left(1-k_{t}\right)}{\omega_{2} \tilde{r}_{l, t}^{r}} .
\end{aligned}
$$


Substituting for $q_{t}, r_{d, t}^{r}$ and $r_{e, t}^{r}$ allows us to rewrite the problem more compactly:

$$
\max _{k_{t}, o_{t}} o_{t}\left\{\tilde{r}_{l, t}^{r}\left(\hat{q}_{t} \omega_{1}-\frac{\omega_{2}}{2} \hat{q}_{t}^{2}\right)-R_{t}^{r}-\xi k_{t}\right\}
$$

where

$$
\hat{q}_{t}=\frac{\omega_{1}+\sqrt{\omega_{1}^{2}-\left(4 \omega_{2}\left(1-k_{t}\right) R_{t}^{r}\right) / \tilde{r}_{l, t}^{r}}}{\omega_{2}} .
$$

The FOCs for leverage $k_{t}$ reads:

$$
k_{t}=1-\frac{\xi\left(R_{t}^{r}+\xi\right) \omega_{1}^{2} \tilde{r}_{l, t}^{r}}{\omega_{2} R_{t}^{r}\left(R_{t}^{r}+2 \xi^{2}\right)} .
$$

Finally, since the first stage problem is linear in the balance sheet size $o_{t}$, the corresponding first order condition requires banks to make no expected profits in excess of the costs of funds:

$$
\underbrace{\tilde{r}_{l, t}^{r}\left(q_{t} \omega_{1}-\frac{\omega_{2}}{2} q_{t}^{2}\right)}_{\text {revenues }}-\underbrace{\left(k_{t} \xi+R_{t}^{r}\right)}_{\text {cost of funds }}=0 .
$$

We can combine the last three equations to derive the banks' risk choice $q_{t}$ as a function of the safe real interest rate:

$$
q_{t}=\frac{\omega_{1}\left(\xi+R_{t}^{r}\right)}{\omega_{2}\left(2 \xi+R_{t}^{r}\right)}
$$

\subsubsection{Bank risk taking in equilibrium}

The bank's equilibrium risk choice discussed above has four important properties, that we summarize below:

PROPOSITION 1: Consider a partial equilibrium in the banking sector for a given level of the expected real rate $R_{t}^{r}$. Let $q_{t}$ denote the optimal risk choice of the bank in partial equilibrium and assume this choice is interior. Recall the definition of the expected productivity of the input producer $\mathrm{f}\left(q_{t}\right) \equiv\left(\omega_{1}-\frac{\omega_{2}}{2} q_{t}\right) q_{t}$. Then:

(2) Risk taking is excessive: $q_{t}<\operatorname{argmax} \mathrm{f}\left(q_{t}\right)$.

(3) Expected productivity increases in the real interest rate: $\frac{\partial \mathrm{f}\left(q_{t}\right)}{\partial R_{t}^{r}}>0$. 
Expected productivity is a concave function of the real interest rate $\frac{\partial^{2} \mathrm{f}\left(q_{t}\right)}{\partial\left(R_{t}^{r}\right)^{2}}<0$

Part 1 of the proposition, which can be easily derived from equation (12), states that a decline in the real risk-free rate $R_{t}^{r}$ induces banks to invest into riskier projects ( $q_{t}$ falls). This is the risk-taking channel at work.

What is the intuition behind it? By choosing its funding structure at stage 1 the bank implicitly determines its risk choice at stage 2 , which is understood and priced in by depositors. Thus, when the bank chooses its leverage, it balances the advantages of deposits (lower costs due to the excess equity premium) with those of equity (mores skin in the game, hence less risk taking at stage 2, thus higher expected return on investment). A reduction in the safe real rate makes the equity premium a more important component of the cost of equity, in relative terms. Thus banks have a stronger incentive to rely on cheaper deposits and thus to lever up. This reduces their skin-in-the-game and induces them to take more risk. For this result it is crucial that the equity premium is constant in absolute terms. As Abbate and Thaler (2019) argue, this assumption is both common in the theoretical literature as well as empirically plausible.

Part 2 states that the bank's risk choice is excessive (i.e. suboptimally high), in the sense that expected productivity would increase if the bank chose a safer investment. The inefficiency of the risk choice results from the agency problem between depositors and equity providers and the fact that deposits are cheaper than equity. In the absence of these frictions, $q_{t}$ would be chosen to maximize expected productivity $\left(\omega_{1}-\frac{\omega_{2}}{2} q_{t}\right) q_{t}$ and would thus be given by $q^{o}=\frac{\omega_{1}}{\omega_{2}}$. The frictions drive a wedge between the optimal risk level $q^{o}$ and the level that is actually chosen $q_{t}$ :

$$
q_{t}=q^{o} \frac{\xi+R_{t}^{r}}{2 \xi+R_{t}^{r}} .
$$

This wedge is smaller than one, i.e. banks choose excessive risk. Furthermore, it increases in $R_{t}^{r}$. Thus, risk taking gets more excessive as the real rate falls, implying a lower expected productivity $\mathrm{f}\left(q_{t}\right)$ as stated in part 3 .

Finally, part 4 states that the effect of $R_{t}^{r}$ on expected productivity $\mathrm{f}\left(q_{t}\right)$ decreases in $R_{t}^{r}$. That is $\mathrm{f}\left(q_{t}\left(R_{t}^{r}\right)\right)$ is a concave function. This result will be crucial for optimal policy. Parts 2 to 4 of proposition 1 are illustrated in figure $1 .^{14}$

\footnotetext{
${ }^{14}$ Notice that the exact shape of the risk return trade-off does not need to be
} 
Figure 1: Expected return on bank assets $\mathrm{f}\left(q_{t}\right)=\mathrm{f}\left(q_{t}\left(R_{t}^{r}\right)\right)$, as a function of the real interest rate $R_{t}^{r}$

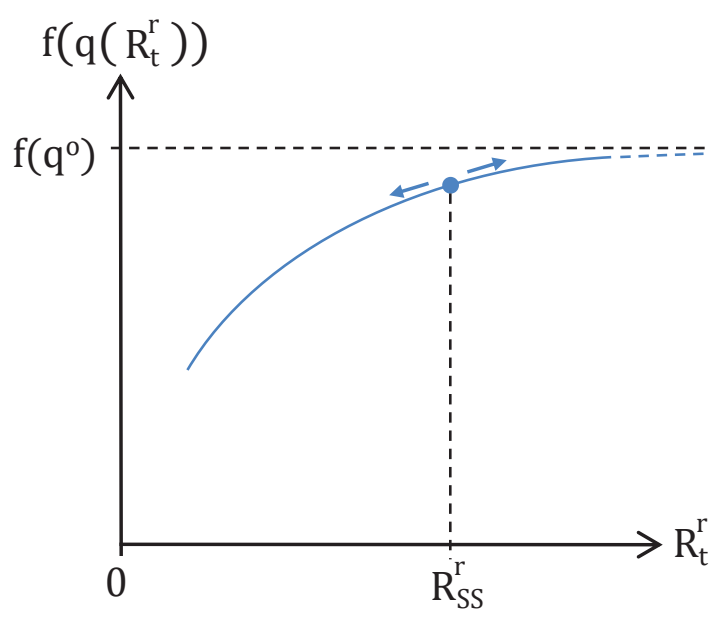

\subsection{Central bank}

To close the model, the central bank needs to set the nominal interest rate according to some criterion and adjust the money supply accordingly. It may follow a Taylor rule or optimize welfare. We leave this criterion unspecified for now. This concludes the description of the model.

\subsection{Comparison to the three-equation New Keynesian model}

Our model embeds the risk-taking channel into the basic textbook NKM. Frictions in the banking sector imply that lower interest rates lead banks to choose riskier investments with a lower expected productivity. This alters two key equations in the standard New Keynesian model: The definitions of aggregate output and of marginal costs. We discuss them in turn. The other equations remain unaltered, and we report them in Appendix A.

First, using equation (7) and aggregating the intermediate goods, aggregate output

quadratic as we assumed for $f\left(q_{t}\right)$ : as Abbate and Thaler (2019) show, proposition 1 generally holds for a broad class of concave functions $\mathrm{f}\left(q_{t}\right)$. Concavity in turn is a natural assumption since it guarantees an interior solution. Even more generally, for the analytical results about optimal policy in section 3 the exact mechanism behind the risk-taking channel is irrelevant. All that will matter is the concavity of $\mathrm{f}\left(q_{t}\left(R_{t}^{r}\right)\right)$. 
can be defined as:

$$
Y_{t}=\frac{A_{t}\left(\omega_{1}-\frac{\omega_{2}}{2} q_{t}\right) q_{t}}{\Delta_{t}} N_{t}=\frac{A_{t} \mathrm{f}\left(q_{t}\right)}{\Delta_{t}} N_{t}
$$

where $\Delta_{t}$ is the standard price dispersion term. This expression implies that, because of the risk-taking channel, aggregate output is not only a function of labor, total factor productivity and price dispersion, but also of the average productivity of the input production technology $\mathrm{f}\left(q_{t}\right)$. This new term is a function of the real interest rate by equation (12):

$$
\mathrm{f}\left(q_{t}\right)=f\left(R_{t}^{r}\right)=\frac{\omega_{1}^{2}}{\omega_{2}} \frac{\xi+R_{t}^{r}}{2 \xi+R_{t}^{r}}-\frac{\omega_{1}^{2}}{2 \omega_{2}}\left(\frac{\xi+R_{t}^{r}}{2 \xi+R_{t}^{r}}\right)^{2}
$$

The risk-taking channel has both steady-state and dynamic implications for aggregate output. From part 2 of Proposition 1, we know that the banking sector frictions lead to excessive (suboptimally high) risk taking, both in and outside the steady state, so that $\mathrm{f}\left(q_{t}\right)<\mathrm{f}\left(q^{o}\right)$, where $\mathrm{f}\left(q^{o}\right)$ is the productivity of input good producers evaluated at the optimal risk level. The inefficient risk choice translates to an inefficiently low level of aggregate output, both in and outside the steady state. Moreover, risk taking gets more excessive as the real interest rate falls (part 3 in Proposition 1). This implies that the lower the real interest rate, the lower the level of aggregate output.

Second, marginal costs are also affected by the risk-taking channel. They are given by equation (8), which we reproduce below:

$$
M C_{t}=\frac{W_{t}}{A_{t}\left(\omega_{1}-\frac{\omega_{2}}{2} q_{t}\right) q_{t}}=\frac{W_{t}}{A_{t} \mathrm{f}\left(q_{t}\right)}
$$

As noted before, this equation differs from that of a standard New Keynesian model in the term $\mathrm{f}\left(q_{t}\right)$. Productivity depends not only on total factor productivity, but also on the risk level chosen by the banks. By the same arguments discussed for output, marginal costs are hence excessively high and decrease in the real interest rate.

After linearization, the model condenses to the two well-known equations, that together with a policy rule for the nominal interest rate define the three-equation NKM : the IS curve and the Phillips curve. While the former is the same as in the textbook model, the risk-taking channel shows up in the Phillips curve (see 
Appendix B2) via the marginal costs:

$$
\pi_{t}=\beta \mathbb{E}_{t} \pi_{t+1}+\kappa(\sigma+\varphi) \hat{x}_{t}-\kappa(1+\varphi) \mathcal{R}_{1} \hat{R}_{t}^{r}+u_{t}
$$

Here $\kappa=\frac{(1-\omega)(1-\beta \omega)}{\omega}$ is the coefficient on marginal costs in the standard New Keynesian Phillips curve, $\hat{x}_{t}$ is the log of the welfare relevant output gap (wrt. to the efficient level) and $\hat{R}_{t}^{r}$ is the expected real rate, the latter two in deviation from the steady state, $\mathcal{R}_{1}$ is a positive coefficient defined in the next section, and $u_{t}$ is a cost-push shock driven by $\theta_{t}$.

To summarize, once the model is condensed, the risk-taking channel shows up as a function $f\left(R_{t}^{r}\right)$ multiplying TFP. Our model is hence isomorphic to a model where TFP is a positive, concave function of the real interest rate. Next, we explore how this channel alters the standard trade off faced by the monetary policy authority.

\section{Optimal monetary policy in the simple model}

To understand the impact of the risk-taking channel on optimal policy, we first derive a second order approximation of the planner's welfare function, and then use it to derive optimal policy.

\subsection{The objective function}

We assume the planner maximizes household utility. As we show in Appendix B1, in case of a small steady-state distortion, a second-order approximation to consumer welfare leads to the following social loss function:

$$
\begin{aligned}
\mathbb{W}=-\mathbb{E}_{\mathrm{t}} & \left\{\sum _ { t = 0 } ^ { \infty } \beta ^ { t } \left[\Theta \widehat{x}_{t}-\frac{1}{2} \frac{\omega}{(1-\beta \omega)(1-\omega)} \theta \pi_{t}^{2}-\frac{1}{2}(\sigma+\varphi) \hat{x}_{t}^{2}+(1-\Theta) \mathcal{R}_{1} \hat{R}_{t}^{r}\right.\right. \\
& \left.\left.-\frac{1}{2}\left((1+\varphi) \mathcal{R}_{1}^{2}+\mathcal{R}_{2}\right)\left(\hat{R}_{t}^{r}\right)^{2}-\mathcal{R}_{1}(\sigma-1) \hat{R}_{t}^{r} \hat{y}_{t}^{e}+\mathcal{R}_{1}(1+\varphi) \hat{R}_{t}^{r} \hat{x}_{t}\right]\right\}
\end{aligned}
$$

where $\hat{y}_{t}^{e}$ denotes the efficient level of output, $\widehat{x}_{t}$ the welfare relevant output gap, both in log deviations from steady state, and where $\hat{R}_{t}^{r}$ denotes the period $t$ expectation of the real interest rate in next period, in deviations from steady state. The first three terms in the loss function are the usual in the standard New Keynesian model and imply that consumer welfare declines in (i) the steady-state output gap distortion, 
(ii) fluctuations of inflation and (iii) fluctuations of the output gap. The term $\Theta$ is the steady-state distortion related to imperfect competition in the intermediate sector, which is defined as $\Theta=1-\frac{1}{\Phi}$ where $\Phi$ is the steady-state markup. The other terms are related to the risk-taking channel and discussed in the Appendix. Here we just note that the fourth term implies that welfare increases in the real interest rate because the efficiency of risk taking increases in the real rate. The coefficients $\mathcal{R}_{1}$ and $\mathcal{R}_{2}$ are a positive function of the steady state real interest rate, and of the equity premium:

$$
\begin{gathered}
\mathcal{R}_{1}=\frac{f_{R}}{f\left(R^{r}\right)}>0 \\
\mathcal{R}_{2}=-\frac{f_{R R} f\left(R^{r}\right)-\left(f_{R}\right)^{2}}{f\left(R^{r}\right)^{2}}>0
\end{gathered}
$$

where $f\left(R^{r}\right)$ denotes the steady state of equation (14), and $f_{R}$ and $f_{R R}$ respectively denote the first and second-order derivatives of $f\left(R^{r}\right)$ with respect to $R^{r}$, which we characterized in proposition $1 .{ }^{15}$

Because our main focus is on stabilization policies, we will follow the literature in assuming that time-invariant subsidies are in place such that the steady state is efficient. This eliminates the steady-state markup $(\Theta=0)$ and the steady-state inefficiency in risk taking, such that $f_{R}=0$, while still $f_{R R}<0$. The loss function then simplifies to:

$$
\mathbb{W}=\frac{1}{2} \mathbb{E}_{\mathrm{t}} \sum_{t=0}^{\infty} \beta^{t}\left[\frac{\omega}{(1-\beta \omega)(1-\omega)} \theta \pi_{t}^{2}+(\sigma+\varphi) x_{t}^{2}+\mathcal{R}_{2}\left(\hat{R}_{t}^{r}\right)^{2}\right]
$$

This expression is identical to the welfare function in the textbook NKM, with the exception of the last term. This is our first key result about optimal policy: The risk-taking channel introduces a real interest rate volatility term into the second order approximation of welfare. To understand why this term appears, recall part 4 of Proposition 1, which states that the expected return of the bank's investment is concave. This implies that a mean preserving spread in the real interest rate reduces the expected return of investment by Jensen's inequality. Volatility in the expected real interest rate thus affects welfare negatively. This intuition is evident from (16): The weight on real rate volatility in the loss function is $\mathcal{R}_{2}=-\frac{f_{R R}}{f\left(R^{r}\right)}$. This weight

\footnotetext{
${ }^{15}$ The expressions for $\mathcal{R}_{1}$ and $\mathcal{R}_{2}$ are reported in Appendix B1. Note that these terms, which measure the strength of the risk-taking channel, increase in the equity premium $\xi$.
} 
is positive due to the concavity of expected productivity in the real rate $\left(f_{R R}<0\right)$. Recall that the equity premium $\xi$ was defined in real terms. This is important here. If the equity premium were instead a nominal object, the nominal rate would appear instead of the real in (16).

\subsection{The central bank's problem}

Under the assumption of an undistorted steady state, the linear approximation of the model reduces to the same IS and Phillips curves as in the textbook NKM. A linear-quadratic approximation of the central bank's problem is then given by:

$$
\max -\frac{1}{2} \mathbb{E}_{\mathrm{t}}\left\{\sum_{t=0}^{\infty} \beta^{t}\left[\pi_{t}^{2}+\lambda x_{t}^{2}+\frac{\kappa}{\theta} \mathcal{R}_{2}\left(\hat{R}_{t}^{r}\right)^{2}\right]\right\}
$$

subject to the IS equation:

$$
x_{t}=\mathbb{E}_{t} x_{t+1}-\frac{1}{\sigma}\left(\hat{R}_{t}-\mathbb{E}_{t} \pi_{t+1}\right)
$$

the Phillips curve:

$$
\pi_{t}=\beta \mathbb{E}_{t} \pi_{t+1}+\kappa(\sigma+\varphi) x_{t}+u_{t}
$$

and the linearized definition of the real rate:

$$
\hat{R}_{t}^{r}=\hat{R}_{t}-\mathbb{E}_{t} \pi_{t+1}
$$

where $\lambda=\frac{\kappa}{\theta}(\sigma+\varphi)$ denotes the weight of output fluctuations relative to inflation fluctuations in the loss function, $\theta$ is the elasticity of substitution between goods in the steady state and $x_{t}$ is the output gap wrt to the steady state. The supply-side cost push shock $u_{t}$ is assumed to follow an AR process with autoregressive coefficient $\rho$. For simplicity, but without loss of generality, we have also assumed that TFP $A_{t}$ is constant so that no shock appears in the IS curve. ${ }^{16}$

\footnotetext{
${ }^{16}$ In a standard NKM without the risk-taking channel it is optimal for the central bank to stabilize both inflation and the output gap $\hat{x}_{t}$ perfectly in response to 'demand' shocks such as temporary productivity, government spending or preference shocks, which affect the flex-price economy as well (divine coincidence Galí, 2015). Since such a zero-inflation-zero-output-gap policy requires the real rate to follow the natural rate, it implies non-zero real rate volatility. The risk-taking channel thus introduces a trade-off that breaks the divine coincidence and leads to the same conclusions as those summarized at the beginning of the next section. These analytical results are thus robust to the nature of shocks.
} 


\subsection{Optimal discretionary policy}

We now derive optimal monetary policy, starting with the simpler case of discretionary policy. That is, we assume that that the central bank cannot credibly commit to any future action and thus cannot influence expectations on future variables. Since there are no endogenous state variables, the central bank problem then simplifies to a sequence of static optimization problems.

Appendix B3.1 derives the first order conditions to the central bank's problem as well as policy functions for the output gap, inflation, the nominal and real interest rates. These functions are of the form: $x_{t}=a u_{t}, \pi_{t}=b u_{t}, \hat{R}_{t}=c u_{t}$ and $\hat{R}_{t+1}^{r}=d u_{t}$, where the coefficients $(a, b, c, d)$ are derived in Appendix B3.1. The absolute values of these coefficients also determine the standard deviation of the four variables of interest, up to a scaling factor which is the standard deviation of the cost-push shock. To understand how these standard deviations change with the risk-taking channel, we derive the rate of change of the four coefficients with respect to the risk-taking channel parameter $\mathcal{R}_{2}$ and check the sign.

We thus arrive to our second main result: Optimal discretionary policy with the risktaking channel implies a lower volatility of the output gap and of the real interest rate, but a higher volatility of inflation, relative to the model without the risk-taking channel. ${ }^{17}$

What is the intuition behind these results? The standard trade-off in the NKM with cost push shocks is that, through the Phillips curve, inflation stabilization comes at the cost of higher output gap volatility. However, through the IS curve, higher output gap volatility also implies higher real interest rate volatility. This is irrelevant in the standard NKM where the IS curve and the interest rates are recursive. But it becomes costly once the risk-taking channel is active, since fluctuations in the real rate lead to less efficient risk choices on average. The risk-taking channel thus tilts the trade-off between output gap and inflation stabilization arising from cost-push shocks in favor of the former. In other words, the risk-taking channel increases the central bank's tolerance to deviations of the real rate from the natural rate.

Finally, we can re-express the nominal rate as a function of expected future inflation to derive an interest rate rule that serves to implement the equilibrium under optimal policy:

\footnotetext{
${ }^{17}$ The effect of the risk-taking channel on the volatility of the nominal rate is ambiguous: For low enough values of $\rho$, the risk-taking channel also implies a lower volatility of the nominal rate.
} 


$$
\hat{R}_{t}=\phi_{\pi}^{d} \mathbb{E}_{t} \pi_{t+1}=\frac{\theta(\lambda \rho+\kappa(1-\rho)(\sigma+\varphi) \varphi)+\kappa(1-\rho) \rho \mathcal{R}_{2} \sigma^{2}}{\rho \theta \lambda+\kappa(1-\rho) \rho \mathcal{R}_{2} \sigma^{2}} \mathbb{E}_{t} \pi_{t+1}
$$

The parameter multiplying expected inflation $\phi_{\pi}^{d}$ is larger than 1 and can be interpreted as an optimal Taylor rule parameter. Deriving $\phi_{\pi}^{d}$ with respect to the risk-taking channel parameter delivers our third result: The risk-taking channel lowers the optimal response of the nominal interest rate to expected inflation, i.e:

$$
\frac{\partial \phi_{\pi}^{d}}{\partial \mathcal{R}_{2}}=-\frac{\theta \kappa^{2}(1-\rho)^{2} \sigma^{3}(\sigma+\varphi)}{\rho\left(\theta \lambda+\kappa(1-\rho) \mathcal{R}_{2} \sigma^{2}\right)^{2}}<0
$$

Again, the intuition is straightforward. A parameter of 1 would imply a stable real interest rate, thus a central bank that cares about stabilizing the real rate chooses a value closer to 1 .

Next, we show that the last two results also hold for a policy maker that optimally chooses the parameter of such a simple rule.

\subsection{Commitment: Optimal simple rules}

As in Clarida et al. (1999), we now assume that the central bank has full commitment but is restricted to simple policy functions that depend only on the exogenous state $u_{t}$. That is we consider an optimal simple rule of the form $x_{t}=-\gamma u_{t}$, where $\gamma$ is chosen under commitment.

In Appendix B3.2 we explicitly set up the problem and solve it to derive the policy functions, which are linear in the cost-push shock $u_{t}$ by construction. Analogously to the previous subsection, we then compute the rate of change of the standard deviations of the endogenous variables with respect to the risk-taking channel parameter $\mathcal{R}_{2}$.

The results confirm those derived for the discretion case: The inclusion of the risktaking channel implies lower output gap and real interest rate volatility and higher inflation volatility under optimal policy. Analogously to the previous subsection, we can express the policy rule for the nominal interest rate as a function of expected future inflation to arrive to an optimal simple Taylor rule. As before, the the risktaking channel lowers the optimal response of the nominal interest rate to expected inflation. 


\subsection{Commitment: Fully optimal policy}

Finally, we turn to Ramsey-optimal policy. The central bank's problem is to solve (17) by choosing conditional paths for inflation, the output gap and the interest rate. Appendix B3.3 provides the Lagrangian and the first-order conditions of this Ramsey problem. Unfortunately, no simple analytical solution is available for the rational expectations equilibrium defined by these conditions. However, it is possible to combine the first-order conditions to derive an implicit instrument rule as in Giannoni and Woodford (2003). This rule applies from $t \geq 2$ and is optimal from a timeless perspective and reads:

$$
\hat{R}_{t}=\rho_{1} \hat{R}_{t-1}+\rho_{2} \Delta \hat{R}_{t-1}+\phi_{E \pi} \mathbb{E}_{t} \pi_{t+1}+\phi_{\pi} \pi_{t}+\phi_{\pi_{-1}} \pi_{t-1}+\phi_{x} \Delta x_{t}
$$

where $\rho_{1}=1, \rho_{2}=\frac{1}{\beta}, \phi_{E \pi}=1, \phi_{\pi}=\frac{\theta \sigma+\theta \varphi}{\mathcal{R}_{2} \sigma}-\frac{1}{\beta}-1, \phi_{\pi-1}=\frac{1}{\beta}, \phi_{x}=\frac{\theta \lambda}{\mathcal{R}_{2}^{2} \kappa \sigma}$.

Similarly as above, the weight on inflation in this Taylor-type rule decreases in the strength of the risk-taking channel. Furthermore, this rule exhibits a nontrivial degree of persistence: $\rho_{1}=1, \rho_{2}>1$, unlike the optimal Taylor rule under no commitment. As Woodford (2003) shows, in the standard NKM the fully optimal interest rate paths do not involve any explicit reference to the lagged interest rate either. ${ }^{18}$ Thus, under fully optimal policy the risk-taking channel introduces a case for persistent policy responses. This is our fourth analytical result.

The risk-taking channel thus provides an additional explanation for interest rate inertia, which is routinely built into Taylor rules in models, and which is typically observed in practice. It augments other theories such as the zero lower bound or the cost of holding money, which regularly motivate researchers to include the interest rate - the nominal one, not the real one as in our case - in the welfare function and which also lead to inertia under optimal policy.

\section{The importance of the risk-taking channel in a quan- titative New Keynesian model}

The analysis so far has delivered a clear description of the implications of the risktaking channel for optimal monetary policy in an otherwise standard New Keynesian

\footnotetext{
${ }^{18}$ Note that the above rule does not nest a rule for the standard NKM. However, as the weight on real rate stabilization $\frac{\kappa}{\theta} \mathcal{R}_{2}^{2}$ goes towards 0 , past interest rates become less important in the determination of the current interest rate, relative to deviations of output and inflation.
} 
model. We have derived four analytical results, which we summarize below:

- R1: Real interest rate volatility affects welfare negatively

- R2: Optimal monetary policy with the risk-taking channel calls for lower real interest rate volatility and higher inflation volatility

- R3: The presence of the risk-taking channel lowers the optimal response to inflation in a simple Taylor-type policy rule

- R4: The risk-taking channel introduces a motive for inertia in the policy rate

In this section we determine whether these four results are also quantitatively important. After all, some previous studies have found that other financial frictions do not have quantitatively significant effects on optimal monetary policy (e.g. Bernanke and Gertler, 2001 or De Fiore and Tristani, 2013).

To quantify the importance of the risk-taking channel, we turn to the quantitative model of Abbate and Thaler (2019). The latter embeds the same model of intermediation and risk taking as above in an otherwise standard medium-scale NewKeynesian model as in Smets and Wouters (2007). This model has three advantages over the simple model of section 2: First, it includes a number of additional building blocks that bring it closer to macroeconomic dynamics. Second, it has been estimated on US data. ${ }^{19}$ Thus, we can rely on a plausible set of empirically determined parameters instead of making arbitrary parametric assumptions. Third, Abbate and Thaler (2019) show that the inclusion of the risk-taking channel improves the fit of the benchmark Smets-and-Wouters model with respect to standard macro time series data, generates a path of risk taking that matches survey evidence on the riskiness of newly issued loans, and gives rise to a procyclical bank leverage as documented by Adrian and Shin (2014). ${ }^{20}$ This gives us confidence that this model of the risk-taking channel is empirically plausible. In sum, the larger model is useful to assess whether the new monetary policy trade-off between inflation and

\footnotetext{
${ }^{19}$ Abbate and Thaler (2019) estimate the model on US data over 1984Q1 to 2007Q3, using seven standard macro series, plus a measure of the equity ratio in the US banking sector, which allows the identification of the banking sector parameters. More details can be found there.

${ }^{20}$ The risk-taking channel improves the posterior odds of the benchmark model by $\exp (3.1)$. The variable $q_{t}$ displays a $60 \%$ correlation with the risk of newly issued loans, see figure 2 in the Appendix. The correlation between the variables considered by Adrian and Shin (2014) (leverage and the bank balance sheet size) is $43 \%$. These are all non-targeted moments. See Abbate and Thaler (2019) for further details.
} 
real interest rate stabilization generated by the risk-taking channel is quantitatively significant.

Since the larger model is essentially a medium scale extension of the simple model, we rely on Abbate and Thaler (2019) for a full description, and limit ourselves to a brief explanation of the differences. The larger model is different in five dimensions. First, it includes capital. As common in the literature, we assume that banks finance the capital stock and give up the assumption that wages need to be prefinanced. The risky input good producer hence becomes a risky capital good producer. Inefficient risk taking affects aggregate output through the productivity of capital, via the same mechanisms discussed in the simple model. Second, the banking sector in the larger model has two additional features that improve the model's quantitative fit: Deposit insurance and a non-zero liquidation value in case of bank default. ${ }^{21}$ These features imply that, in case of bank failure, depositors get the maximum of the amount covered by deposit insurance and the value of investment that can be recovered from a failed project. Similar to the equity premium, deposit insurance improves the cost advantage of deposits over equity, thereby worsening the risk-taking problem. The liquidation value is irrelevant for the bank's choice, because it is assumed to be smaller than deposit insurance. ${ }^{22}$ Importantly, these additions leave Proposition 1 and thus the mechanism unchanged. Third, the larger model has additional features that improve its quantitative fit: Habits in consumption, investment adjustment costs, Kimball aggregation, monopolistic competition in the labor market, wage stickiness, price and wage indexation. These features are standard in medium-scale NK models. Fourth, the larger model includes a more complex shock structure. While in the simple model we have considered only optimal responses to a costpush shock, the larger model features eight shocks. These are the seven shocks in the Smets and Wouters (2007) model, plus a shock to the equity premium. Fifth, we do not assume that the steady state is undistorted.

\subsection{The numerical experiment}

We proceed as follows. We set the model parameters to their posterior mean estimates (cf. table 2 in Abbate and Thaler 2019). Then, we numerically determine the

\footnotetext{
${ }^{21}$ The deposit insurance scheme, which covers the gap between the insurance cap and the liquidation value for the depositors of failing banks, is financed through a variable tax on capital.

${ }^{22}$ Deposit insurance does not affect the optimal frictionless level of risk. By contrast, the liquidation value increases the optimal risk level, thereby easing the excessiveness of risk taking.
} 
optimal simple implementable monetary policy rule using a second order approximation as in Schmitt-Grohe and Uribe (2007). We focus on a simple policy rule - as opposed to Ramsey optimal policy - both because such a rule is realistically implementable and because their coefficients can easily be related to our analytical results $\mathrm{R} 3$ and $\mathrm{R} 4$. We do so in two model versions: The full model with the risktaking channel (henceforth bank model), and a model version without this channel, that corresponds to a standard Smets and Wouters economy (henceforth benchmark model). We then compare the performance of these two optimal rules in the bank model. This comparison has an interesting interpretation. Suppose that the actual economy features the risk-taking channel (the bank model), but the central bank is unaware of this channel and believes that risk taking cannot be influenced by the interest rate. The central bank would then design optimal policy based on a wrong model (the benchmark model). Our comparison then answers the question of how important it is to understand the risk-taking channel, in terms of optimal policy and welfare. ${ }^{23}$

In particular, we look for the policy rule that maximizes welfare among the class of simple, implementable interest-rate feedback rules given by: ${ }^{24}$

$$
\hat{R}_{t}=\phi_{\pi} \hat{\pi}_{t+s}+\phi_{y} \hat{y}_{t+s}+\rho_{r} \hat{R}_{t-1}
$$

where the index $s$ allows for forward-looking or contemporaneous rules (respectively by setting $s=1$ or $s=0$ ), and the hat symbol denotes log deviations from the steady state (in case of $s>0$ in expectations). We impose that the inertia parameter $\rho$ has to be non-negative. The policy rule (23) is a standard Taylor rule, which allows for the two elements that we have found to be optimal in subsections 3.3 to 3.5: A (weaker) response to inflation and inertia. ${ }^{25}$

As before, the welfare criterion is the household's conditional lifetime utility. To

\footnotetext{
${ }^{23}$ For this experiment we use the parameters estimated for the bank model for both the bank and benchmark economy. I.e. we keep all parameters fixed for this comparison, we just switch the banking sector on or off. The latter is done by fixing the equity ratio and the risk choice at their steady state levels. Alternatively, we could assume that the central bank determines its policy based on an estimation of the benchmark model. Findings are robust to this alternative.

${ }^{24}$ Implementability requires uniqueness of the rational expectations equilibrium. Simplicity requires the interest rate to be a function of readily observable variables. For a complete discussion, see Schmitt-Grohe and Uribe (2007).

${ }^{25}$ One might wonder whether it would be useful for the central bank to respond to leverage as an observable proxy for risk taking. However, since leverage and risk taking are dependent on the nominal rate and inflation, both of which already appear in the Taylor rule, there is nothing to be gained from doing so, at least up to first order.
} 
Table 1: Optimal simple rules: The second (third) column describes the timing (restrictions) of the policy rule. Italics indicate restricted parameters.

\begin{tabular}{ccc|ccc|ccc}
\hline & \multicolumn{2}{c|}{ rule } & \multicolumn{3}{c|}{ benchmark model } & \multicolumn{3}{c}{ bank model } \\
& $s$ & restriction & $\rho_{r}$ & $\phi_{\pi_{t+s}}$ & $\phi_{y_{t+s}}$ & $\rho$ & $\phi_{\pi_{t+s}}$ & $\phi_{y_{t+s}}$ \\
\hline I & 0 & $\rho_{r}=0$ & 0 & 7.100 & 0.115 & 0 & 3.080 & 0.126 \\
II & 0 & & 0.000 & 7.100 & 0.115 & 1.059 & 0.510 & 0.005 \\
III & 1 & $\rho_{r}=0$ & 0 & 17.222 & 0.148 & 0 & 4.294 & 0.172 \\
IV & 1 & & 0.236 & 12.084 & 0.124 & 1.114 & 0.072 & 0.074 \\
\hline
\end{tabular}

compare welfare levels, we define the measure $\Omega$ as the fraction of the consumption stream that a household would need to receive as a transfer under the suboptimal rule $S$ to be equally well off as under the optimal rule $O$. $\Omega$ is implicitly defined by the following equation:

$$
\mathbb{E}_{0} \sum_{t=0}^{\infty} \beta^{t} U\left(C_{t}^{O}, N_{t}^{O}\right)=\mathbb{E}_{0} \sum_{t=0}^{\infty} \beta^{t} U\left((1+\Omega) C_{t}^{S}, N_{t}^{S}\right) .
$$

\section{$4.2 \quad$ Findings}

Our numerical analysis delivers four results, which mirror the four theoretical results above. $^{26}$ The first two results are evident from Table 1, which reports the optimal coefficients for four different specifications of the monetary policy rule: contemporaneous and forward-looking, without inertia and with optimal inertia.

First, the optimal coefficient on inflation deviations is always significantly smaller in the bank model than in the benchmark model. This confirms that our analytical result $\mathrm{R} 3$ from the simple model - a lower optimal weight on inflation in the Taylor rule - carries over to the medium scale model used here.

Second, if the central bank can optimize over its smoothing parameter, then full interest rate smoothing is optimal in the bank model, but not in the benchmark model (rows II and IV). ${ }^{27}$ This confirms result R4 that the risk-taking channel introduces a rationale for interest rate smoothing.

But how do these differences in policy rules translate into differences in the behavior of macroeconomic variables? Our third finding is the answer to this question and is provided in Table 2. The table displays how much the mean and volatility of

\footnotetext{
${ }^{26}$ The results are qualitatively robust with respect to the estimation sample and the choice of the priors and calibrated parameters.

${ }^{27}$ Values of $\rho_{r}$ slightly above 1 are not uncommon e.g. Rotemberg and Woodford (1999).
} 
Table 2: Differences in moments associated with the optimal simple rules in the benchmark and in the bank model: Columns 4-10 indicate the \% change of mean and standard deviations of key variables when the central bank switches from the benchmark-optimal to the bankoptimal rule in the bank model. The first entry, for example, indicates that under the bank-optimal policy rule the standard deviation of the real rate $R^{r}$ is $48 \%$ lower than if the rule optimal for the benchmark model had been applied in the bank model. The last column reports the welfare cost (in \% of the consumption stream) associated with implementing in the bank model the optimal policy rule of the benchmark model.

\begin{tabular}{ccc|ccc|cccc|c}
\hline & \multicolumn{2}{c|}{ rule } & \multicolumn{3}{|c|}{ standard deviation } & \multicolumn{4}{c|}{ mean } & \\
& $s$ & restriction & $R^{r}$ & $\pi$ & $y$ & $R^{r}$ & $\pi$ & $y$ & $f(q)$ & $\Omega$ \\
\hline I & 0 & $\rho_{r}=0$ & -47.975 & 52.470 & -0.843 & 0.002 & -0.051 & 0.311 & 0.045 & 0.476 \\
II & 0 & & -77.760 & 64.393 & -9.545 & 0.007 & -0.038 & 0.439 & 0.061 & 0.898 \\
III & 1 & \multirow{2}{*}{$\rho_{r}=0$} & -55.417 & 57.719 & -2.781 & 0.011 & -0.037 & 0.413 & 0.062 & 0.687 \\
IV & 1 & & -76.3112 & 71.906 & -10.373 & 0.004 & -0.054 & 0.458 & 0.057 & 0.813 \\
\hline
\end{tabular}

key variables change when the central bank switches from the benchmark-optimal rule to the bank-optimal rule in the bank model. By responding less aggressively to inflation and by smoothing the nominal interest rate, the central bank optimally limits the volatility of the real interest rate (column 4 ). The lower volatility of $R_{t}^{r}$ translates into a higher average return on investment $\mathrm{f}\left(q_{t}\right)$, due to the concavity of this function in $R_{t}^{r}$ (column 10). ${ }^{28}$ However, this higher average return on investment comes at the cost of higher inflation volatility (column 5), in line with the analytical result R2. The increase in volatility is sizable (50-70\%). Hence, the new tradeoff between inflation and real rate stabilization implies a significant deviation from inflation stabilization: The central bank reacts a lot less strongly to deviations of inflation from the target in order to achieve a more stable real rate

Finally, we assess how different the equilibria associated to the two optimal rules are in terms of welfare, and therefore how important it is for the central bank to take the risk-taking channel into account. To do so, we compute the welfare cost $\Omega$ of applying the rule that is optimal for the benchmark model in the bank model. These costs, expressed in \% of the lifetime consumption stream, are reported in the last column of Table 2. They are significant for all policy rule specifications. For the best-performing policy, the cost of applying the benchmark policy in the bank model are around $0.81 \%$ of the lifetime consumption stream. The effect of the

\footnotetext{
${ }^{28}$ Note that the slight increase in $R_{t}^{r}$ accounts only for a marginal fraction of the increase in $f\left(q_{t}\right)$.
} 
risk-taking channel on the policy maker's objective function that we approximated analytically above (result R1) turns out to be economically significant.

In sum, the risk-taking channel is economically significant for optimal monetary policy both in terms of the prescribed policy and the welfare cost of deviating from it.

\section{Conclusions}

This paper analyses the implications of the risk-taking channel for optimal monetary policy. To this end we first embed a model of asset risk taking into the textbook NKM. Then, we characterize optimal policy analytically using a linear quadratic approximation. We find that the risk-taking channel (i) introduces real rate volatility into the otherwise standard objective function of the central bank, (ii) calls for lower real rate volatility and higher inflation volatility, (iii) lowers the optimal response to inflation in a Taylor-type policy rule, (iv) introduces a motive for inertia in the policy rule. Lastly, we extend the model to a medium-scale DSGE model of the type routinely used at central banks to evaluate the quantitative importance of the risk-taking channel for monetary policy. We show that the four conclusions from the simple model not only carry over, but also matter significantly. Conducting optimal policy as if the risk-taking channel were not present entails high costs in terms of welfare.

Our model of the risk-taking channel is analytically tractable and our analysis delivers clear results for optimal monetary policy. To this end, we have abstracted form other dimensions of the risk-taking channel such as risks on the liabilities side of banks, effects of the zero lower bound or long spells of low interest rates. At the same time however, our qualitative lessons about optimal policy can be of relevance for any theory that relates TFP to the level of the real interest rate, such as some theories of capital misallocation (e.g. Gopinath et al., 2017).

Furthermore, our model economy features no regulatory tools. While these tools are important, they are outside the scope of the present paper. ${ }^{29}$ Instead we focus on what the monetary policy maker can do about risk taking in the (realistic) case that the risk-taking channel cannot be fully addressed by regulation. Using monetary policy to address shortcomings of "imperfect" regulation is advocated in a similar

\footnotetext{
${ }^{29}$ For an analysis of macroprudential regulation in an economy with bank risk-taking see for example Collard et al. (2017).
} 
context e.g. by Stein (2013) and Bean et al. (2015), and was discussed as an option during the January 2020 FOMC meeting.

\section{References}

Angela Abbate and Dominik Thaler. Monetary policy and the asset risk-taking channel. Journal of Money, Credit and Banking, 51(8):2115-2144, December 2019.

Tobias Adrian and Hyun Song Shin. Procyclical Leverage and Value-at-Risk. Review of Financial Studies, 27(2):373-403, 2014.

Elena Afanasyeva and Jochen Guentner. Bank market power and the risk channel of monetary policy. Journal of Monetary Economics, 111(C):118-134, 2020.

Franklin Allen, Elena Carletti, and Robert Marquez. Credit market competition and capital regulation. The Review of Financial Studies, 24(4):983-1018, 2011.

Ignazio Angeloni and Ester Faia. Capital regulation and monetary policy with fragile banks. Journal of Monetary Economics, 60(3):311-324, April 2013.

Ignazio Angeloni, Ester Faia, and Marco Lo Duca. Monetary policy and risk taking. Journal of Economic Dynamics and Control, 52:285-307, March 2015.

Charles Bean, Christian Broda, Takatoshi Ito, and Randall Kroszner. Low for Long? Causes and Consequences of Persistently Low Interest Rates. Technical report, 17th CEPR-ICMB Geneva Report on the World Economy, October 2015.

Ben S. Bernanke and Mark Gertler. Should Central Banks Respond to Movements in Asset Prices? American Economic Review, 91(2):253-257, May 2001.

Johannes Bubeck, Angela Maddaloni, and Jose-Luis Peydro. Negative Monetary Policy Rates and Systemic Banks' Risk-Taking: Evidence from the Euro Area Securities Register. Journal of Money, Credit and Banking, 52(S1):197-231, October 2020.

Claudia M. Buch, Sandra Eickmeier, and Esteban Prieto. In search for yield? Survey-based evidence on bank risk taking. Journal of Economic Dynamics and Control, 43(C):12-30, 2014. 
Ian Christensen, Cesaire Meh, and Kevin Moran. Bank Leverage Regulation and Macroeconomic Dynamics. Working Papers 11-32, Bank of Canada, 2011.

Richard Clarida, Jordi Galí, and Mark Gertler. The science of monetary policy: A new keynesian perspective. Journal of Economic Literature, 37(4):1661-1707, December 1999.

Fabrice Collard, Harris Dellas, Behzad Diba, and Olivier Loisel. Optimal Monetary and Prudential Policies. American Economic Journal: Macroeconomics, 9(1): 40-87, January 2017.

Fiorella De Fiore and Oreste Tristani. Optimal Monetary Policy in a Model of the Credit Channel. Economic Journal, 123(571):906-931, 092013.

Oliver de Groot. The Risk Channel of Monetary Policy. International Journal of Central Banking, 10(2):115-160, June 2014.

Giovanni Dell'Ariccia, Luc Laeven, and Robert Marquez. Real interest rates, leverage, and bank risk-taking. Journal of Economic Theory, 149(0):65 - 99, 2014.

FOMC. Minutes of the january 2020 fomc meeting, Jan 2020.

Jordi Galí. Monetary Policy, Inflation, and the Business Cycle: An Introduction to the New Keynesian Framework and Its Applications Second edition. Number 10495 in Economics Books. Princeton University Press, 2015.

Mark Gertler, Nobuhiro Kiyotaki, and Albert Queralto. Financial crises, bank risk exposure and government financial policy. Journal of Monetary Economics, 59 (S):S17-S34, 2012.

Marc P. Giannoni and Michael Woodford. Optimal Interest-Rate Rules: II. Applications. NBER Working Papers 9420, National Bureau of Economic Research, Inc, January 2003.

Gita Gopinath, Sebnem Kalemli-Oezcan, Loukas Karabarbounis, and Carolina Villegas-Sanchez. Capital Allocation and Productivity in South Europe. The Quarterly Journal of Economics, 132(4):1915-1967, 2017.

Garyand Gorton and Andrew Winton. Liquidity provision, bank capital, and the macroeconomy. Journal of Money, Credit and Banking, 49(1):5-37, 2017. 
Florian Heider, Farzad Saidi, and Glenn Schepens. Life below Zero: Bank Lending under Negative Policy Rates. The Review of Financial Studies, 32(10):3728-3761, 022019 .

Thomas F. Hellmann, Kevin C. Murdock, and Joseph E. Stiglitz. Liberalization, moral hazard in banking, and prudential regulation: Are capital requirements enough? The American Economic Review, 90(1):147-165, 2000.

Vasso Ioannidou, Steven Ongena, and Jose-Lui Peydro. Monetary Policy, RiskTaking and Pricing: Evidence from a Quasi-Natural Experiment. Discussion Paper 2009-04S, European Banking Center, June 2014.

Gabriel Jimenez, Steven Ongena, Jose Luis Peydro, and Jesus Saurina. Hazardous Times for Monetary Policy: What Do Twenty-Three Million Bank Loans Say About the Effects of Monetary Policy on Credit Risk-Taking? Econometrica, 82 (2):463-505, 2014.

Angela Maddaloni and Jose-Luis Peydro. Bank risk-taking, securitization, supervision, and low interest rates: Evidence from the euro-area and the u.s. lending standards. The Review of Financial Studies, 24(6):2121-2165, 2011. ISSN $08939454,14657368$.

David Martinez-Miera and Rafael Repullo. Monetary policy, macroprudential policy, and financial stability. Annual Review of Economics, 11(1):809-832, 2019.

Ives Mersch. Asset price inflation and monetary policy, Jan 2020.

Federico Ravenna and Carl E. Walsh. Optimal monetary policy with the cost channel. Journal of Monetary Economics, 53(2):199-216, March 2006.

Julio J. Rotemberg and Michael Woodford. Interest Rate Rules in an Estimated Sticky Price Model. In Monetary Policy Rules, NBER Chapters, pages 57-126. National Bureau of Economic Research, Inc, 1999.

Stephanie Schmitt-Grohe and Martin Uribe. Optimal, Simple, and Implementable Monetary and Fiscal Rules. Journal of Monetary Economics, 54(6):1702-1725, September 2007.

Frank Smets and Rafael Wouters. Shocks and Frictions in US Business Cycles: A Bayesian DSGE Approach. American Economic Review, 97(3):586-606, 2007. 
Jeremy Stein. Overheating in credit markets: Origins, measurement, and policy responses, 2013. Remarks at the "Restoring Household Financial Stability after the Great Recession: Why Household Balance Sheets Matter" research symposium sponsored by the Federal Reserve Bank of St. Louis, St. Louis, Missouri.

Michael Woodford. Interest and Prices: Foundations of a Theory of Monetary Policy. Princeton University Press, 2003. 


\section{Online Appendix}

\section{Appendix A: Full set of recursive equations in the simple model}

The following 12 equations (24) - (35) define the equilibrium. Note that only equations (24) - (26) differ from the standard NKM and that the model collapses to the standard NKM if $\mathrm{f}\left(q_{t}\right)$ is a constant.

Marginal costs:

$$
M C_{t}=\frac{W_{t}}{A_{t}\left(\omega_{1}-\frac{\omega_{2}}{2} q_{t}\right) q_{t}}=\frac{W_{t}}{A_{t} \mathrm{f}\left(q_{t}\right)}
$$

Output:

$$
A_{t} \mathrm{f}\left(q_{t}\right) N_{t}=\Delta_{t} C_{t}
$$

Risk taking channel:

$$
\begin{gathered}
f\left(q_{t}\right)=f\left(R_{t+1}^{r}\right)=\frac{\omega_{1}^{2}}{\omega_{2}} \frac{\xi+R_{t}^{r}}{2 \xi+R_{t}^{r}}-\frac{\omega_{1}^{2}}{2 \omega_{2}}\left(\frac{\xi+R_{t}^{r}}{2 \xi+R_{t}^{r}}\right)^{2} \\
R_{t}^{r}=\frac{R_{t}}{\mathbb{E}_{t} \pi_{t+1}}
\end{gathered}
$$

Household optimization:

$$
\begin{gathered}
u_{C}\left(C_{t}, N_{t}\right)=\beta \frac{R_{t}}{\mathbb{E}_{t} \pi_{t+1}} u_{C}\left(C_{t+1}, N_{t+1}\right) \\
-\frac{u_{N}\left(C_{t}, N_{t}\right)}{u_{C}\left(C_{t}, N_{t}\right)}=w_{t}
\end{gathered}
$$

Price setting:

$$
\begin{gathered}
\pi_{t}^{\star}=\frac{\epsilon_{p}}{\epsilon_{p}-1} \frac{Z_{1, t}}{Z_{2, t}} \\
\Lambda_{t}=\frac{\beta u_{C}\left(C_{t+1}, N_{t+1}\right)}{u_{C}\left(C_{t}, N_{t}\right)}
\end{gathered}
$$




$$
\begin{gathered}
Z_{1, t}=\Lambda_{t} m c_{t} y_{t}+\beta \lambda_{p} \mathbb{E}_{t}\left[\left(\pi_{t+1}\right)^{\epsilon_{p}} Z_{1, t+1}\right] \\
Z_{2, t}=\Lambda_{t} y_{t}+\beta \lambda_{p} \mathbb{E}_{t}\left[\left(\pi_{t+1}\right)^{\epsilon_{p}-1} Z_{2, t+1}\right] \\
1=(1-\lambda)\left(\pi_{t}^{\star}\right)^{1-\epsilon_{p}}+\lambda\left(\pi_{t}\right)^{\epsilon_{p}-1} \\
\Delta_{t}=(1-\lambda)\left(\pi_{t}^{\star}\right)^{-\epsilon_{p}}+\lambda \Delta_{t-1}\left(\pi_{t}\right)^{\epsilon_{p}}
\end{gathered}
$$

The following equations are recursive:

$$
\begin{gathered}
d_{t}+e_{t}=m_{t-1} / \pi_{t}+w_{t} N_{t}-C_{t}+x_{t} \\
m_{t}=m_{t-1} / \pi_{t}+w_{t} N_{t}-d_{t}-e_{t}-C_{t}+R_{t}\left(d_{t}+e_{t}\right)+\Pi_{t}+x_{t}+\xi e_{t}-T_{t} \\
\Pi_{t}=C_{t}-w_{t} z_{t} r_{l, t} \\
q_{t}=\quad \frac{\omega_{1}}{\omega_{2}} \frac{\xi+R_{t}^{r}}{2 \xi+R_{t}^{r}} \\
k_{t}=\frac{R_{t}^{r}}{R_{t}^{r}+2 \xi} \\
d_{t}+e_{t}=o_{t} \\
\frac{e_{t}}{e_{t}+d_{t}}=k_{t} N_{t}
\end{gathered}
$$




\section{Appendix B: Deriving optimal policy}

\section{B1: Deriving the welfare function}

Our goal is to derive a second-order approximation to the utility of the household when the economy is close to the steady state, around a zero-inflation steady state and in the case of a small steady state distortion. We follow Galí (2015) and Ravenna and Walsh (2006). The procedure involves 8 steps. We preliminary describe the notation that will be used throughout the derivations:

Table 3: Notation

\begin{tabular}{cl}
\hline$X_{t}$ & variable in level \\
$X$ & steady state level \\
$x_{t}$ & variable in log: $\ln \left(X_{t}\right)$ \\
$\hat{x}_{t}$ & $\log$ deviation from steady state: $x_{t}-x=\ln \left(X_{t}\right)-\ln (X)=\ln \left(X_{t} / X\right)$ \\
$\hat{X}_{t}$ & absolute deviation from steady state \\
$R_{t}^{r}$ & gross real interest rate \\
\hline
\end{tabular}

Step 1: Take a second-order Taylor expansion of the utility function in time $t$ around the steady state $\mathrm{C}, \mathrm{N}$ :

$U\left(C_{t}, N_{t}\right) \simeq U+U_{C}\left(C_{t}-C\right)+U_{N}\left(N_{t}-N\right)+\frac{1}{2} U_{C C}\left(C_{t}-C\right)^{2}+\frac{1}{2} U_{N N}\left(N_{t}-N\right)^{2}+$ t.i.p.

where t.i.p. stands for terms independent of policy, $U=U(C, N)$ denotes the utility function evaluated at the steady state and $U_{x}=U_{x}(C, N), U_{x x}=U_{x x}(C, N)$ respectively denote the first and second order derivative of the utility function with respect to variable $x$, evaluated at the steady state. Multiply and divide by steadystate consumption or employment, where appropriate:

$U\left(C_{t}, N_{t}\right) \simeq U+U_{C} \frac{\left(C_{t}-C\right)}{C} C+U_{N} \frac{\left(N_{t}-N\right)}{N} N+\frac{1}{2} U_{C C} \frac{\left(C_{t}-C\right)^{2}}{C^{2}} C^{2}+\frac{1}{2} U_{N N} \frac{\left(N_{t}-N\right)^{2}}{N^{2}} N^{2}+t . i . p$.

Step 2 Exploit the aggregate resource constraint: $Y_{t}=C_{t}$ 
$U\left(C_{t}, N_{t}\right) \simeq U+U_{C}\left[\frac{\left(Y_{t}-Y\right)}{Y} Y+\frac{1}{2} \frac{U_{C C}}{U_{c}} \frac{\left(Y_{t}-Y\right)^{2}}{Y^{2}} Y^{2}\right]+U_{N}\left[\frac{\left(N_{t}-N\right)}{N} N+\frac{1}{2} \frac{U_{N N}}{U_{N}} \frac{\left(N_{t}-N\right)^{2}}{N^{2}} N^{2}\right]+$ t.i.p.

Note that, given our utility function, $\frac{U_{C C}}{U_{C}} C=-\sigma$ and $\frac{U_{N N}}{U_{N}} N=\varphi$. Use that $\frac{X_{t}-X}{X} \simeq \widehat{x}_{t}+\frac{1}{2} \widehat{x}_{t}^{2}$ and drop terms of order higher than 2 , i.e. use that $\left(\widehat{x}_{t}+\frac{1}{2} \widehat{x}_{t}^{2}\right)^{2}=$ $\widehat{x}_{t}^{2}+\widehat{x}_{t}^{3}+\frac{1}{4} \widehat{x}_{t}^{4} \simeq \widehat{x}_{t}^{2}$ :

$U\left(C_{t}, N_{t}\right) \simeq U+U_{C}\left(\left(\widehat{y}_{t}+\frac{1}{2} \widehat{y}_{t}^{2}\right) Y-\frac{1}{2} \sigma \widehat{y}_{t}^{2} Y\right)+U_{N}\left(\left(\widehat{n}_{t}+\frac{1}{2} \widehat{n}_{t}^{2}\right) N+\frac{1}{2} \varphi \widehat{n}_{t}^{2} N\right)+$ t.i.p.

Rearranging:

$$
U\left(C_{t}, N_{t}\right) \simeq U+U_{C} Y\left(\widehat{y}_{t}+\frac{1-\sigma}{2} \widehat{y}_{t}^{2}\right)+U_{N} N\left(\widehat{n}_{t}+\frac{1+\varphi}{2} \widehat{n}_{t}^{2}\right)+\text { t.i.p. }
$$

Step 3: Express aggregate employment as a function of output. From our model, we can express aggregate employment as:

$$
N_{t}=\frac{\Delta_{t} Y_{t}}{A_{t} f\left(R_{t}^{r}\right)}
$$

where $\Delta_{t}$ expresses the resource loss due to the price dispersion term, and where $f\left(R_{t}^{r}\right)$ is the dispersion term related to the risk-taking channel, which depends on the expected real interest rate $R_{t}^{r}$. We take logs of both sides:

$$
\ln \left(N_{t}\right)=\ln \left(\Delta_{t}\right)+\ln \left(Y_{t}\right)-\ln \left(A_{t}\right)-\ln f\left(R_{t}^{r}\right)
$$

We derive the second-order Taylor expansion of $\ln f\left(R_{t}^{r}\right)$ :

$$
\ln f\left(R_{t}^{r}\right) \approx \ln f\left(R^{r}\right)+\frac{f_{R}}{f\left(R^{r}\right)}\left(R_{t}^{r}-R^{r}\right)+\frac{1}{2} \frac{f_{R R} f\left(R^{r}\right)-\left(f_{R}\right)^{2}}{f\left(R^{r}\right)^{2}}\left(R_{t}^{r}-R^{r}\right)^{2}
$$

Define now the two coefficients:

$$
\mathcal{R}_{1}=\frac{f_{R}}{f\left(R^{r}\right)}=\frac{2 \xi^{2}}{\left(R^{r}+\xi\right)\left(R^{r}+2 \xi\right)\left(R^{r}+3 \xi\right)}>0
$$




$$
\mathcal{R}_{2}=-\frac{f_{R R} f\left(R^{r}\right)-\left(f_{R}\right)^{2}}{f\left(R^{r}\right)^{2}}=\frac{2\left(3\left(R^{r}\right)^{2} \xi^{2}+12 R^{r} \xi^{3}+11 \xi^{4}\right)}{\left(R^{r}+\xi\right)^{2}\left(R^{r}+2 \xi\right)^{2}\left(R^{r}+3 \xi\right)^{2}}>0
$$

Replace the second-order Taylor expansion of $\ln f\left(R_{t}^{r}\right)$ into the expression for aggregate employment, and subtract from both sides the log of the steady state. Since $\ln (\Delta)=\ln (1)=\delta=0$ and $\ln (A)=\ln (1)=a=0$ we have:

$$
\hat{n}_{t}=\delta_{t}+\hat{y}_{t}-a_{t}-\mathcal{R}_{1} \hat{R}_{t}^{r}+\frac{\mathcal{R}_{2}}{2}\left(\hat{R}_{t}^{r}\right)^{2}
$$

We can plug this into our utility function:

$$
\begin{aligned}
U\left(C_{t}, N_{t}\right) \simeq U+U_{C} Y & \left(\widehat{y}_{t}+\frac{1-\sigma}{2} \widehat{y}_{t}^{2}\right)+U_{N} N\left[\delta_{t}+\hat{y}_{t}-a_{t}-\mathcal{R}_{1} \hat{R}_{t}^{r}+\frac{\mathcal{R}_{2}}{2}\left(\hat{R}_{t}^{r}\right)^{2}\right] \\
& +U_{N} N \frac{1+\varphi}{2}\left[\delta_{t}+\hat{y}_{t}-a_{t}-\mathcal{R}_{1} \hat{R}_{t}^{r}+\frac{\mathcal{R}_{2}}{2}\left(\hat{R}_{t}^{r}\right)^{2}\right]^{2}+\text { t.i.p. }
\end{aligned}
$$

Now, we use the following Lemma, proven in ch. 3.4 of Galí (2015): $\delta_{t}=\frac{\theta}{2} \operatorname{var}\left\{p_{t}(i)\right\}$. This is valid in the neighborhood of a symmetric steady state and up to a second order approximation. Using this Lemma, and the fact that terms of order higher than 2 can be dropped out of the approximation, yields:

$$
\begin{aligned}
& U\left(C_{t}, N_{t}\right) \simeq U+U_{C} Y\left(\widehat{y}_{t}+\frac{1-\sigma}{2} \widehat{y}_{t}^{2}\right) \\
+ & U_{N} N\left(\frac{\theta}{2} \operatorname{var}\left\{p_{t}(i)\right\}+\hat{y}_{t}-a_{t}-\mathcal{R}_{1} \hat{R}_{t}^{r}+\frac{\mathcal{R}_{2}}{2}\left(\hat{R}_{t}^{r}\right)^{2}+\frac{1+\varphi}{2}\left(\hat{y}_{t}-a_{t}-\mathcal{R}_{1} \hat{R}_{t}^{r}\right)^{2}\right)+\text { t.i.p. }
\end{aligned}
$$

Step 4: Divide everything by $U_{c} C$ so to express the approximation as a percentage of steady state consumption:

$$
\begin{aligned}
& \frac{U\left(C_{t}, N_{t}\right)-U}{U_{C} Y} \simeq \widehat{y}_{t}+\frac{1-\sigma}{2} \widehat{y}_{t}^{2} \\
+ & \frac{U_{N} N}{U_{C} Y}\left(\frac{\theta}{2} \operatorname{var}\left\{p_{t}(i)\right\}+\hat{y}_{t}-a_{t}-\mathcal{R}_{1} \hat{R}_{t}^{r}+\frac{\mathcal{R}_{2}}{2}\left(\hat{R}_{t}^{r}\right)^{2}+\frac{1+\varphi}{2}\left(\hat{y}_{t}-a_{t}-\mathcal{R}_{1} \hat{R}_{t}^{r}\right)^{2}\right)+\text { t.i.p. }
\end{aligned}
$$

Combining the household first order condition with respect to labor, and input producer's labor demand condition and the definition of marginal costs, we get that: 


$$
-\frac{U_{N}}{U_{C}}=\frac{W}{P}=\frac{A q\left(\omega_{1}-\omega_{2} q\right)}{\Phi}
$$

Where we have defined $\Phi=\theta /(\theta-1)$ as the steady-state markup. ${ }^{30}$ We then get that:

$$
\frac{U_{N} N}{U_{C} Y}=-\frac{A q\left(\omega_{1}-\frac{\omega_{2}}{2} q\right)}{\Phi} \frac{N}{A q\left(\omega_{1}-\frac{\omega_{2}}{2} q\right) N}=-\frac{1}{\Phi}
$$

Define $\Theta$ such that:

$$
1-\Theta=\frac{1}{\Phi}
$$

We can exploit the definition of $\Theta$ as well as the assumption of a small steady state distortion (so any interaction with terms of order $\geq 2$ can be eliminated) to re-express the utility approximation as:

$$
\begin{aligned}
\frac{U\left(C_{t}, N_{t}\right)-U}{U_{C} Y} \simeq \widehat{y}_{t}+ & \frac{1-\sigma}{2} \widehat{y}_{t}^{2}-\frac{\theta}{2} \operatorname{var}\left\{p_{t}(i)\right\}-\hat{y}_{t}+a_{t}+\mathcal{R}_{1} \hat{R}_{t}^{r}-\frac{\mathcal{R}_{2}}{2}\left(\hat{R}_{t}^{r}\right)^{2} \\
& -\frac{1+\varphi}{2}\left(\hat{y}_{t}-a_{t}-\mathcal{R}_{1} \hat{R}_{t}^{r}\right)^{2}+\Theta\left(\hat{y}_{t}-a_{t}-\mathcal{R}_{1} \hat{R}_{t}^{r}\right)+\text { t.i.p. }
\end{aligned}
$$

Note also that $a_{t}$ is independent of policy and hence can go into the t.i.p. After some rearranging of terms, we get:

$$
\begin{aligned}
\frac{U\left(C_{t}, N_{t}\right)-U}{U_{C} Y} & \simeq \Theta \hat{y}_{t}+(1-\Theta) \mathcal{R}_{1} \hat{R}_{t}^{r}-\frac{\mathcal{R}_{2}}{2}\left(\hat{R}_{t}^{r}\right)^{2} \\
- & \frac{1}{2}\left[\theta \operatorname{var}\left\{p_{t}(i)\right\}-(1-\sigma) \hat{y}_{t}^{2}+(1+\varphi)\left(\hat{y}_{t}-a_{t}-\mathcal{R}_{1} \hat{R}_{t}^{r}\right)^{2}\right]+\text { t.i.p. }
\end{aligned}
$$

Step 5: Collect terms related to output deviations and re-express them as output gap deviations. Open the square bracket $\left(\hat{y}_{t}-a_{t}-\mathcal{R}_{1} \hat{R}_{t}^{r}\right)^{2}$ and collect terms related to output deviations squared:

\footnotetext{
${ }^{30}$ In the absence of the subsidy on input goods, there would be an additional term related to the cost channel in the above equation, but the rest of the derivations would be unaffected.
} 


$$
\begin{gathered}
\frac{U\left(C_{t}, N_{t}\right)-U}{U_{C} Y} \simeq \Theta \hat{y}_{t}+(1-\Theta) \mathcal{R}_{1}+1-\frac{\mathcal{R}_{2}}{2}\left(\hat{R}_{t}^{r}\right)^{2}-\frac{1}{2}\left[\theta \operatorname{var}\left\{p_{t}(i)\right\}+(\sigma+\varphi) \hat{y}_{t}^{2}+(1+\varphi) a_{t}^{2}\right] \\
-\frac{1}{2}\left[(1+\varphi)\left(\mathcal{R}_{1} \hat{R}_{t}^{r}\right)^{2}-2(1+\varphi) \hat{y}_{t} \mathcal{R}_{1} \hat{R}_{t}^{r}+2(1+\varphi) a_{t} \mathcal{R}_{1} \hat{R}_{t}^{r}\right]+t . i . p .
\end{gathered}
$$

Re-express productivity as a function of the efficient level of output $y_{t}^{e}$ where needed. Recall that $y_{t}^{e}$ is independent of policy and can be expressed as:

$$
\widehat{y}_{t}^{e}=\frac{1+\varphi}{\sigma+\varphi} a_{t}
$$

Denoting the output gap as $x_{t}=y_{t}-y_{t}^{e}$ we can express the utility approximation as:

$$
\begin{aligned}
\frac{U\left(C_{t}, N_{t}\right)-U}{U_{C} Y} \simeq & \Theta \widehat{x}_{t}+(1-\Theta) \mathcal{R}_{1} \hat{R}_{t}^{r}-\frac{\mathcal{R}_{2}}{2}\left(\hat{R}_{t}^{r}\right)^{2}-\frac{1}{2}\left[\theta \operatorname{var}\left\{p_{t}(i)\right\}+(\sigma+\varphi) \hat{x}_{t}^{2}\right] \\
& -\frac{1}{2}(1+\varphi)\left(a_{t}^{2}+\mathcal{R}_{1}^{2}\left(\hat{R}_{t}^{r}\right)^{2}-2 \hat{y}_{t} \mathcal{R}_{1} \hat{R}_{t}^{r}+2 a_{t} \mathcal{R}_{1} \hat{R}_{t}^{r}\right)+\text { t.i.p. }
\end{aligned}
$$

Step 6: Express var $\left\{p_{t}(i)\right\}$ as a function of inflation. From Woodford (2000) and Lemma 2 in Ch. 4 of Galí (2015) we know that: $\operatorname{var}\left\{p_{t}(i)\right\} \approx \operatorname{\omega var}\left\{p_{t-1}(i)\right\}+$ $\frac{\omega}{1-\omega} \pi_{t}^{2}$, where $\omega$ is the Calvo parameter. So we have that:

$$
\sum_{t=0}^{\infty} \beta^{t} \operatorname{var}\left\{p_{t}(i)\right\}=\frac{\omega}{(1-\beta \omega)(1-\omega)} \sum_{t=0}^{\infty} \beta^{t} \pi_{t}^{2}+t . i . p
$$

Step 7: Get the approximated present discounted value of the welfare loss function:

$$
\begin{gathered}
\mathbb{W}=-\mathbb{E}_{0} \sum_{t=0}^{\infty} \beta^{t} \frac{U\left(C_{t}, N_{t}\right)-U}{U_{c} C}=-E_{0}\left\{\sum _ { t = 0 } ^ { \infty } \beta ^ { t } \left[\Theta \widehat{x}_{t}+(1-\Theta) \mathcal{R}_{1} \hat{R}_{t}^{r}-\frac{\mathcal{R}_{2}}{2}\left(\hat{R}_{t}^{r}\right)^{2}\right.\right. \\
\left.\left.-\frac{1}{2}\left[\operatorname{\theta var}\left\{p_{t}(i)\right\}+(\sigma+\varphi) \hat{x}_{t}^{2}+(1+\varphi)\left(a_{t}^{2}+\mathcal{R}_{1}^{2}\left(\hat{R}_{t}^{r}\right)^{2}-2 \hat{y}_{t} \mathcal{R}_{1} \hat{R}_{t}^{r}+2 a_{t} \mathcal{R}_{1} \hat{R}_{t}^{r}\right)\right]\right]\right\}
\end{gathered}
$$

Using step 6 we get: 


$$
\begin{aligned}
\mathbb{W}=-\mathbb{E}_{0}\left\{\sum _ { t = 0 } ^ { \infty } \beta ^ { t } \left[\Theta \widehat{x}_{t}+(1-\Theta) \mathcal{R}_{1} \hat{R}_{t}^{r}-\frac{\mathcal{R}_{2}}{2}\left(\hat{R}_{t}^{r}\right)^{2}-\frac{1}{2} \frac{\omega \theta}{(1-\omega)(1-\omega \beta)} \pi_{t}^{2}-\frac{1}{2}(\sigma+\varphi) \hat{x}_{t}^{2}\right.\right. \\
\left.\left.-\frac{1}{2}(1+\varphi)\left(a_{t}^{2}+\mathcal{R}_{1}^{2}\left(\hat{R}_{t}^{r}\right)^{2}-2 \hat{y}_{t} \mathcal{R}_{1} \hat{R}_{t}+2 a_{t} \mathcal{R}_{1} \hat{R}_{t}^{r}\right)\right]\right\}
\end{aligned}
$$

Collect the terms related to the real interest rate, remember that $a_{t}$ is independent of policy and re-express $\hat{y}_{t}$ in terms of the output gap. This yields:

$$
\begin{aligned}
\mathbb{W}=-\mathbb{E}_{0} & \left\{\sum _ { t = 0 } ^ { \infty } \beta ^ { t } \left[\Theta \widehat{x}_{t}-\frac{1}{2} \frac{\omega \theta}{(1-\omega)(1-\omega \beta)} \pi_{t}^{2}-\frac{1}{2}(\sigma+\varphi) \hat{x}_{t}^{2}+(1-\Theta) \mathcal{R}_{1} \hat{R}_{t}^{r}\right.\right. \\
& \left.\left.-\frac{1}{2}\left((1+\varphi) \mathcal{R}_{1}^{2}+\mathcal{R}_{2}\right)\left(\hat{R}_{t}^{r}\right)^{2}-\mathcal{R}_{1}(\sigma-1) \hat{R}_{t}^{r} \hat{y}_{t}^{e}+\mathcal{R}_{1}(1+\varphi) \hat{R}_{t}^{r} \hat{x}_{t}\right]\right\}
\end{aligned}
$$

The first three terms in this approximation are standard. Welfare loss increases with distortions in the current output gap (from the first best level), and with the volatility of inflation and in the output gap. The remaining terms derive from the inclusion of the risk-taking channel:

- $-(1-\Theta) \mathcal{R}_{1} \hat{R}_{t}^{r}$ : A higher real interest rate, decreases the inefficiency of risk taking, reducing the welfare loss.

- $\left((1+\varphi) \mathcal{R}_{1}^{2}+\mathcal{R}_{2}\right)\left(\hat{R}_{t}^{r}\right)^{2}$ : The real rate affects the efficiency of the banks' investment choice and through that the productivity of labor (TFP). Volatility in the real interest rate makes TFP more volatile and reduces it on average (due to the concavity of $f$ ). These two effects, which are captured by the two coefficients, imply that real rate volatility lowers welfare.

- $\mathcal{R}_{1}(\sigma-1) \hat{R}_{t}^{r} \hat{y}_{t}^{e}$ : For a risk aversion parameter $\sigma$ greater than unity, this term is clearly positive, implying that welfare losses increase in the covariance between the real interest rate gap and the efficient level of output (i.e. productivity). A negative productivity shock (a fall in the efficient level of output) coupled with a fall in the real interest rate would imply an even larger negative productivity shock, amplifying the welfare loss. This is because a lower real rate increases the inefficiency of risk-taking, lowering the marginal productiv- 
ity of labor.

- $-\mathcal{R}_{1} \hat{R}_{t}^{r}(1+\varphi) \hat{x}_{t}$ : Welfare losses decrease in the covariance between the output gap the real interest rate gap. The intuition is the same as for the previous covariance term: A positive output gap coupled with an increase in the real interest rate implies an additional increase in the output gap, increasing welfare. This is because a higher real rate decreases the inefficiency of risk-taking, increasing the marginal productivity of labor and through that aggregate output.

Step 8: Assume correction of the steady state distortion through fiscal instruments. If we assume that the steady state is undistorted then $\Theta=0$ and $\mathcal{R}_{1}=0$ and $\hat{x}_{t}=x_{t}$. The second equality follows from the first derivative of $f\left(R^{r}\right)$ being equal to zero, given the optimal steady state risk choice. The approximated present discounted value of the welfare loss simplifies to:

$$
\mathbb{W}=-\mathbb{E}_{0}\left\{\sum_{t=0}^{\infty} \beta^{t}\left[-\frac{1}{2} \frac{\omega \theta}{(1-\omega)(1-\omega \beta)} \pi_{t}^{2}-\frac{1}{2}(\sigma+\varphi) x_{t}^{2}-\frac{1}{2} \mathcal{R}_{2}\left(\hat{R}_{t}^{r}\right)^{2}\right]\right\}
$$

Hence, only the variance of the real interest rate remains as an additional term in the welfare loss function.

\section{B2: The linearized Phillips curve}

We can express the Phillips curve as (Galí (2015), ch.3):

$$
\pi_{t}=\beta \mathbb{E}_{\mathrm{t}}\left[\pi_{t+1}\right]-\kappa \tilde{\phi}_{t}
$$

with $\tilde{\phi}_{t}$ being the deviation between the average and the desired markup and $\kappa=$ $\frac{(1-\omega)(1-\beta \omega)}{\omega}$. Note that the average price markup is equal to the inverse of real marginal costs, defined in equation (24):

$$
\phi_{t}=p_{t}-\left(w_{t}-a_{t}-\ln f\left(R_{t}^{r}\right)\right)
$$

where small-case letters denote logs. We can then substitute the household's labor choice $\left(\varphi n_{t}+\sigma c_{t}=w_{t}-p_{t}\right)$ and use $y_{t}=c_{t}$, yielding: 


$$
\phi_{t}=-\left(\varphi n_{t}+\sigma y_{t}\right)+a_{t}+\ln f\left(R_{t}^{r}\right)
$$

Substitute for $n_{t}$ using $n_{t}=y_{t}-a_{t}-\ln f\left(R_{t}^{r}\right)$

$$
\phi_{t}=-(\sigma+\varphi) y_{t}+(1+\varphi) a_{t}+(1+\varphi) \ln f\left(R_{t}^{r}\right)
$$

Under flexible prices, the markup is equal to the desired level $\left(\Phi_{t}^{n}=\theta_{t} /\left(\theta_{t}-1\right)\right)$ :

$$
\phi_{t}^{n}=-(\sigma+\varphi) y_{t}^{n}+(1+\varphi) a_{t}+(1+\varphi) \ln f\left(R_{t}^{r, n}\right)
$$

Get an expression for $\tilde{\phi}_{t}$, the deviation between the average and the desired markup:

$$
\tilde{\phi}_{t}=-(\sigma+\varphi)\left(y_{t}-y_{t}^{n}\right)+(1+\varphi)\left(\ln f\left(R_{t}^{r}\right)-\ln f\left(R_{t}^{r, n}\right)\right)
$$

Use the identity $y_{t}-y_{t}^{n}=\left(y_{t}-y_{t}^{e}\right)+\left(y_{t}^{e}-y_{t}^{n}\right)$ :

$$
\tilde{\phi}_{t}=-(\sigma+\varphi)\left(y_{t}-y_{t}^{e}\right)-(\sigma+\varphi)\left(y_{t}^{e}-y_{t}^{n}\right)+(1+\varphi)\left(\ln f\left(R_{t}^{r}\right)-\ln f\left(R_{t}^{r, n}\right)\right)
$$

Use the definition of the welfare relevant output gap:

$$
\tilde{\phi}_{t}=-(\sigma+\varphi) x_{t}-(\sigma+\varphi)\left(y_{t}^{e}-y_{t}^{n}\right)+(1+\varphi)\left(\ln f\left(R_{t}^{r}\right)-\ln f\left(R_{t}^{r, n}\right)\right)
$$

Subtract the steady state, and denote with "hat" deviations from the steady state.

$$
\begin{aligned}
\tilde{\phi}_{t}-0=-(\sigma+\varphi) \hat{x}_{t}- & (\sigma+\varphi)\left(\hat{y}_{t}^{e}-\hat{y}_{t}^{n}\right) \\
& +(1+\varphi)\left[\ln f\left(R_{t}^{r}\right)-\ln f\left(R^{r}\right)-\ln f\left(R_{t}^{r, n}\right)+\ln f\left(R^{r, n}\right)\right]
\end{aligned}
$$

A first order Taylor expansion of the bracket in the second line yields $\mathcal{R}_{1} \hat{R}_{t}^{r}-\mathcal{R}_{1} \hat{R}_{t}^{r, n}$ (see Appendix B1 step 3) so we can write

$$
\tilde{\phi}_{t}=-(\sigma+\varphi) \hat{x}_{t}+(1+\varphi) \mathcal{R}_{1} \hat{R}_{t}^{r}-(1+\varphi) \mathcal{R}_{1} \hat{R}_{t}^{r, n}-(\sigma+\varphi)\left(\hat{y}_{t}^{e}-\hat{y}_{t}^{n}\right)
$$

Using the definitions of $\hat{y}_{t}^{e}$ and $\hat{y}_{t}^{n}(44)$ and (46) we can rewrite this as: 


$$
\tilde{\phi}_{t}=-(\sigma+\varphi) \hat{x}_{t}+(1+\varphi) \mathcal{R}_{1} \hat{R}_{t}^{r}-\hat{\phi}_{t}
$$

Substitute the above equation into the first version of the Phillips curve (45):

$$
\pi_{t}=\beta \mathbb{E}_{\mathrm{t}}\left[\pi_{t+1}\right]+\kappa(\sigma+\varphi) \hat{x}_{t}-\kappa(1+\varphi) \mathcal{R}_{1} \hat{R}_{t}^{r}+u_{t}
$$

Where we have defined the cost-push shock as $u_{t}=\kappa \hat{\phi}_{t}$, i.e. the term capturing short-run deviations of the desired markup caused by movements in the parameter $\theta_{t}$.

Under the assumption of an efficient steady state the expression simplifies to the standard Phillips curve, since $\mathcal{R}_{1}=0$.

$$
\pi_{t}=\beta \mathbb{E}_{\mathrm{t}}\left[\pi_{t+1}\right]+\kappa(\sigma+\varphi) x_{t}+u_{t}
$$

\section{B3: Optimal monetary policy}

Assuming no steady-state distortions, the monetary policy problem is:

$$
\begin{gathered}
\max -\frac{1}{2} \mathbb{E}_{0}\left\{\sum_{t=0}^{\infty} \beta^{t}\left[\pi_{t}^{2}+\lambda x_{t}^{2}+\frac{\kappa}{\theta} \mathcal{R}_{2} \hat{R}_{t}^{r 2}\right]\right\} \\
x_{t}=\mathbb{E}_{\mathrm{t}} x_{t-1}-\frac{1}{\sigma}\left(\hat{R}_{t}-\mathbb{E}_{t} \pi_{t+1}\right) \quad \forall t \\
\pi_{t}=\beta \mathbb{E}_{\mathrm{t}} \pi_{t+1}+\kappa(\sigma+\varphi) x_{t}+u_{t} \quad \forall t \\
\hat{R}_{t}^{r}=\hat{R}_{t}-\mathbb{E}_{t} \pi_{t+1} \quad \forall t
\end{gathered}
$$

where $\kappa=\frac{(1-\omega)(1-\beta \omega)}{\omega}$ is the coefficient on marginal costs in the New Keynesian Phillips curve, $\lambda=\frac{\kappa}{\theta}(\sigma+\varphi)$ denotes the weight of output gap fluctuations relative to inflation fluctuations in the loss function, $\theta$ is the elasticity of substitution between goods, and where we have already substituted $\hat{R}_{t}^{r}=\hat{R}_{t}-\mathbb{E}_{t} \hat{\pi}_{t+1}$. The term $u_{t}$ is a cost-push shock that follows an AR process with autoregressive coefficient $\rho$. 


\section{B3.1: Discretion}

We start with the simpler case, assuming that the central bank cannot credibly commit itself to any future action and cannot therefore influence expectations on future variables. The central bank problem simplifies to one of sequential optimization, i.e. the central bank chooses output and inflation in order to minimize the period losses $U_{t}=\pi_{t}^{2}+\lambda x_{t}^{2}+\frac{\kappa}{\theta} \mathcal{R}_{2}\left(\hat{R}_{t}-\mathbb{E}_{t} \pi_{t+1}\right)^{2}$ subject to the contemporaneous IS and Phillips curve. Under optimal discretion, the first order conditions for the central bank problem are:

$$
\begin{gathered}
\frac{\partial U_{t}}{\partial \pi_{t}}=-\pi_{t}+\psi_{t} \\
\frac{\partial U_{t}}{\partial x_{t}}=-\lambda x_{t}+\chi_{t}-\kappa(\sigma+\varphi) \psi_{t} \\
\frac{\partial U_{t}}{\partial \hat{R}_{t}}=-\frac{\kappa}{\theta} \mathcal{R}_{2}\left(\hat{R}_{t}-\mathbb{E}_{t} \pi_{t+1}\right)+\frac{1}{\sigma} \chi_{t}
\end{gathered}
$$

The above conditions imply the following equilibrium relationship between inflation, the output gap and the real interest rate, under optimal discretionary monetary policy:

$$
\pi_{t}=-\frac{\lambda}{\kappa(\sigma+\varphi)} x_{t}+\frac{\sigma \frac{\kappa}{\theta} \mathcal{R}_{2}}{\kappa(\sigma+\varphi)}\left(\hat{R}_{t}-\mathbb{E}_{t} \hat{\pi}_{t+1}\right)
$$

Next, we derive the policy functions for the key variables of interest. We find them using the method of undetermined coefficients. Since there are no endogenous states, the policy functions must be linear functions in the cost-push shock $u_{t}$. Therefore, we assume the following policy functions: $x_{t}=a u_{t}, \pi_{t}=b u_{t} \hat{R}_{t}=c u_{t}$ and $\hat{R}_{t}^{r}=d u_{t}$. Since the cost-push shock is $\operatorname{AR}(1)$, we also know that $E x_{t+1}=a \rho u_{t}$ and $E \pi_{t+1}=b \rho u_{t}$. By combining these functions with the Phillips curve (49), the IS curve (48), the definition of the real rate and the central bank's optimality condition (51), we can derive the following coefficients:

$$
\begin{gathered}
a=-\frac{\theta \kappa(\sigma+\varphi)}{\theta\left(-\beta \lambda \rho+\kappa^{2}(\sigma+\varphi)^{2}+\lambda\right)+\kappa(\rho-1) \mathcal{R}_{2} \sigma^{2}(\beta \rho-1)} \\
b=\frac{\theta \lambda-\kappa(\rho-1) \mathcal{R}_{2} \sigma^{2}}{\theta\left(-\beta \lambda \rho+\kappa^{2}(\sigma+\varphi)^{2}+\lambda\right)+\kappa(\rho-1) \mathcal{R}_{2} \sigma^{2}(\beta \rho-1)}
\end{gathered}
$$




$$
\begin{gathered}
c=\frac{\theta(\lambda \rho-\kappa(\rho-1) \sigma(\sigma+\varphi))-\kappa(\rho-1) \rho \mathcal{R}_{2} \sigma^{2}}{\theta\left(-\beta \lambda \rho+\kappa^{2}(\sigma+\varphi)^{2}+\lambda\right)+\kappa(\rho-1) \mathcal{R}_{2} \sigma^{2}(\beta \rho-1)} \\
d=-\frac{\theta \kappa(\rho-1) \sigma(\sigma+\varphi)}{\theta\left(-\beta \lambda \rho+\kappa^{2}(\sigma+\varphi)^{2}+\lambda\right)+\kappa(\rho-1) \mathcal{R}_{2} \sigma^{2}(\beta \rho-1)}
\end{gathered}
$$

The absolute values of these coefficients also determine the standard deviations of output gap, inflation and the nominal and real interest rates, up to a scaling factor which is the standard deviation of the cost-push shock. We are interested in establishing how these standard deviations change with the risk-taking channel. To do so, we derive the rate of change of the four coefficients with respect to the risk-taking channel parameter $\mathcal{R}_{2}-$ e.g. $\sigma_{x, \mathcal{R}_{2}}=\frac{\partial a}{\partial \mathcal{R}_{2}} a^{-1}$ - and check the sign:

$$
\begin{gathered}
\sigma_{x, \mathcal{R}_{2}}=-\frac{\kappa(1-\rho) \sigma^{2}(1-\beta \rho)}{\theta\left(\lambda(1-\beta \rho)+\kappa^{2}(\sigma+\varphi)^{2}\right)+\kappa(1-\rho) \mathcal{R}_{2} \sigma^{2}(1-\beta \rho)}<0 \\
\sigma_{\pi, \mathcal{R}_{2}}=\frac{\theta \kappa^{3}(1-\rho) \sigma^{2}(\sigma+\varphi)^{2}}{\left(\theta \lambda+\kappa(1-\rho) \mathcal{R}_{2} \sigma^{2}\right)\left(\theta\left(\lambda(1-\beta \rho)+\kappa^{2}(\sigma+\varphi)^{2}\right)+\kappa(1-\rho) \mathcal{R}_{2} \sigma^{2}(1-\beta \rho)\right)}>0 \\
\sigma_{R, \mathcal{R}_{2}}=\frac{\theta \kappa^{2}(1-\rho) \sigma^{2}(\sigma+\varphi)(\sigma(\rho(\beta(1-\rho)+\kappa+1)-1)+\kappa \rho \varphi)}{\left(\theta(\lambda \rho+\kappa(1-\rho) \sigma(\sigma+\varphi))+\kappa(1-\rho) \rho \mathcal{R}_{2} \sigma^{2}\right)\left(\theta\left(\lambda(1-\beta \rho)+\kappa^{2}(\sigma+\varphi)^{2}\right)+\kappa(1-\rho) \mathcal{R}_{2} \sigma^{2}(1-\beta \rho)\right)} \\
\sigma_{R^{r}, \mathcal{R}_{2}}=-\frac{\kappa 8)}{\theta\left(\lambda(1-\beta \rho)+\kappa^{2}(\sigma+\varphi) \sigma^{2}\right)+\kappa(1-\rho) \mathcal{R}_{2} \sigma^{2}(1-\beta \rho)}<0
\end{gathered}
$$

Given that $\rho<1$ and $\beta<1$, it is straightforward to see that all terms in the numerators and denominators of (56), (57) and (59) are positive. Thus $\sigma_{x, \mathcal{R}_{2}}$ and $\sigma_{R^{r}, \mathcal{R}_{2}}$ are negative, implying that the standard deviation of the output gap under optimal policy is lower when the risk-taking channel is present. By contrast, $\sigma_{\pi, \mathcal{R}_{2}}$ is negative, indicating that the standard deviation of inflation increases with the risk-taking channel.

The sign of $\sigma_{R, \mathcal{R}_{2}}$ in equation (58) is ambiguous. While the denominator is clearly positive, the sign of the numerator depends on the value of the autoregressive parameter $\rho$. For low enough values of this parameter, the derivative of the standard deviation with respect to the risk-taking channel parameter is negative. We can see this by considering the case of an i.i.d. shock $(\rho=0)$. In this case, equations (56) to (59) become: 


$$
\begin{gathered}
\sigma_{x, \mathcal{R}_{2}}=\sigma_{R, \mathcal{R}_{2}}=\sigma_{R^{r}, \mathcal{R}_{2}}=-\frac{\kappa \sigma^{2}}{\theta\left(\kappa^{2}(\sigma+\varphi)^{2}+\lambda\right)+\kappa \mathcal{R}_{2} \sigma^{2}}<0 \\
\sigma_{\pi, \mathcal{R}_{2}}=\frac{\theta \kappa^{3}(\sigma+\varphi)^{2}}{\left(\theta \lambda+\kappa \mathcal{R}_{2} \sigma^{2}\right)\left(\theta\left(\kappa^{2}(\sigma+\varphi)^{2}+\lambda\right)+\kappa \mathcal{R}_{2} \sigma^{2}\right)}>0
\end{gathered}
$$

To derive a policy rule that implements the above equilibrium, we re-express the nominal interest rate as a function of expected future inflation (see Clarida et al. (1999)). The parameter multiplying expected inflation can be interpreted as an optimal Taylor rule parameter $\phi_{\pi}^{d}$, which describes how the central bank should react to expected inflation under optimal discretionary policy:

$$
\hat{R}_{t}=\phi_{\pi}^{d} \mathbb{E}_{t} \pi_{t+1 t}=\frac{\theta(\lambda \rho+\kappa(1-\rho)(\sigma+\varphi) \varphi)+\kappa(1-\rho) \rho \mathcal{R}_{2} \sigma^{2}}{\rho \theta \lambda+\kappa(1-\rho) \rho \mathcal{R}_{2} \sigma^{2}} \mathbb{E}_{t} \pi_{t+1}
$$

We can see that the presence of the risk-taking channel lowers the optimal response of the nominal interest rate to inflation, i.e.:

$$
\frac{\partial \phi_{\pi}^{d}}{\partial \mathcal{R}_{2}}=-\frac{\theta \kappa^{2}(1-\rho)^{2} \sigma^{3}(\sigma+\varphi)}{\rho\left(\theta \lambda+\kappa(1-\rho) \mathcal{R}_{2} \sigma^{2}\right)^{2}}<0
$$

Note that it suffices to take a derivative since the sign of equation (60) is clearly negative.

\section{B3.2: Commitment - Looking for optimal simple rules}

Following Clarida et al. (1999), we consider a rule for the target output gap contingent on the fundamental shock $u_{t}$

$$
x_{t}^{c}=-\gamma u_{t}, \forall t
$$

Combine this equation with the Phillips curve (49) and the IS curve (48), and get expressions for $\pi_{t}$ and $\hat{R}_{t}^{r}$ that also depend on the fundamental shock:

$$
\pi_{t}^{c}=\beta \mathbb{E}_{t} \pi_{t+1}^{c}-\kappa(\sigma+\varphi) \gamma u_{t}+u_{t}
$$




$$
\hat{R}_{t}^{r, c}=\gamma \sigma(1-\rho) u_{t}+\mathbb{E}_{t} \pi_{t+1}^{c}
$$

Substitute the nominal interest rate into the Phillips curve, and collect terms:

$$
\begin{gathered}
\pi_{t}^{c}=\beta \mathbb{E}_{t} \pi_{t+1}^{c}+[1-\kappa(\sigma+\varphi) \gamma] u_{t} \\
\pi_{t}^{c}=\mathbb{E}_{t} \sum_{i=0}^{\infty}\left\{\beta^{i} \rho^{i}[1-\kappa(\sigma+\varphi) \gamma] u_{t}\right\} \\
\pi_{t}^{c}=\frac{1-\kappa(\sigma+\varphi) \gamma}{1-\beta \rho} u_{t}
\end{gathered}
$$

The optimal policy problem can be re-expressed as choosing the value of $\gamma$ that maximizes the following objective function:

$$
\left(\frac{1-\kappa(\sigma+\varphi) \gamma}{1-\beta \rho}\right)^{2} u_{t}^{2}+\lambda \gamma^{2} u_{t}^{2}+\frac{\kappa}{\theta} \mathcal{R}_{2}(\gamma \sigma(1-\rho))^{2} u_{t}^{2}
$$

Note that in the above equation we have substituted the expressions for the output gap, the real rate and inflation using equations (62), (63) and (64).

The FOC yields the following solution for $\gamma$ :

$$
\gamma=\frac{(\sigma+\varphi) \kappa}{(1-\rho \beta)^{2}\left(\frac{\kappa^{2}(\sigma+\varphi)^{2}}{(1-\beta \rho)^{2}}+\lambda+\frac{\kappa(1-\rho)^{2} \mathcal{R}_{2} \sigma^{2}}{\theta}\right)}
$$

This solution can be substituted in equations (62), (63) and (64) to get the policy functions for the output gap, inflation and the nominal and real interest rates.

$$
\begin{gathered}
x_{t}=-\gamma u_{t} \\
\pi_{t}=\frac{\left(1-\frac{\theta \kappa^{2}(\sigma+\varphi)^{2}}{\theta\left(\lambda(1-\beta \rho)+\kappa^{2}(\sigma+\varphi)^{2}\right)+\kappa(1-\rho)^{2} \mathcal{R}_{2} \sigma^{2}(1-\beta \rho)^{2}}\right)}{1-\beta \rho} u_{t} \\
R_{t}=-\frac{\left(\theta(\lambda \rho(1-\beta \rho)-\kappa(1-\rho) \sigma(\sigma+\varphi))-\kappa(1-\rho)^{2} \rho \mathcal{R}_{2} \sigma^{2}(1-\beta \rho)\right)}{\theta\left(\lambda(1-\beta \rho)^{2}+\kappa^{2}(\sigma+\varphi)^{2}\right)+\kappa(1-\rho)^{2} \mathcal{R}_{2} \sigma^{2}(1-\beta \rho)^{2}} u_{t} \\
R_{t}^{r}=\frac{\theta \kappa(1-\rho) \sigma(\sigma+\varphi)}{\theta\left(\lambda(1-\beta \rho)^{2}+\kappa^{2}(\sigma+\varphi)^{2}\right)+\kappa(1-\rho)^{2} \mathcal{R}_{2} \sigma^{2}(1-\beta \rho)^{2}} u_{t}
\end{gathered}
$$

The parameters multiplying the shock also denote the standard deviation of the variables of interest (assuming that the cost-push shock has a unit variance). Anal- 
ogously to what we did in section B3.1, we can compute the rate of change of these standard deviations with respect to the risk-taking channel parameter $\mathcal{R}_{2}$ :

$$
\begin{gathered}
\sigma_{x, \mathcal{R}_{2}}=-\frac{\kappa(1-\rho)^{2} \sigma^{2}}{\theta\left(\frac{\kappa^{2}(\sigma+\varphi)^{2}}{(1-\beta \rho)^{2}}+\lambda+\frac{\kappa(1-\rho)^{2} \mathcal{R}_{2} \sigma^{2}}{\theta}\right)}<0 \\
\sigma_{\pi, \mathcal{R}_{2}}=\frac{\theta \kappa^{3}(1-\rho)^{2} \sigma^{2}(\sigma+\varphi)^{2}}{\left(\theta \lambda+\kappa(1-\rho)^{2} \mathcal{R}_{2} \sigma^{2}\right)\left(\theta\left(\lambda(1-\beta \rho)^{2}+\kappa^{2}(\sigma+\varphi)^{2}\right)+\kappa(1-\rho)^{2} \mathcal{R}_{2} \sigma^{2}(1-\beta \rho)^{2}\right)}>0 \\
\sigma_{R, \mathcal{R}_{2}}=-\frac{\theta \kappa^{2}(1-\rho)^{2} \sigma^{2}(1-\beta \rho)(\sigma+\varphi)\left(\sigma\left(-\rho(\beta+\kappa)+\beta \rho^{2}+(1-\rho)\right)-\kappa \rho \varphi\right)}{\left(\theta(\lambda \rho(1-\beta \rho)+\kappa(1-\rho) \sigma(\sigma+\varphi))+\kappa(1-\rho)^{2} \rho \mathcal{R}_{2} \sigma^{2}(1-\beta \rho)\right)\left(\theta\left(\lambda(1-\beta \rho)^{2}+\kappa^{2}(\sigma+\varphi)^{2}\right)+\kappa(1-\rho)^{2} \mathcal{R}_{2} \sigma^{2}(1-\beta \rho)^{2}\right)} \\
(72) \\
\sigma_{R^{r}, \mathcal{R}_{2}}=-\frac{\kappa(1-\rho)^{2} \sigma^{2}(1-\beta \rho)^{2}}{\theta\left(\lambda(1-\beta \rho)^{2}+\kappa^{2}(\sigma+\varphi)^{2}\right)+\kappa(1-\rho)^{2} \mathcal{R}_{2} \sigma^{2}(1-\beta \rho)^{2}}<0
\end{gathered}
$$

$\sigma_{x, \mathcal{R}_{2}}$ and $\sigma_{R^{r}, \mathcal{R}_{2}}$ are evidently negative while $\sigma_{\pi, \mathcal{R}_{2}}$ is evidently positive, as in the case without commitment. The sign of $\sigma_{R, \mathcal{R}_{2}}$ is ambiguous, as before. However, for low enough values of $\rho$ the derivative of the standard deviation with respect to the risk-taking channel parameter is negative. We can see this by setting $\rho$ to zero, which yields $\frac{\partial \sigma_{r} / \partial \mathcal{R}_{2}}{\sigma_{r}}=-\frac{\kappa \sigma^{2}}{\theta\left(\kappa^{2}(\sigma+\varphi)^{2}+\lambda\right)+\kappa \mathcal{R}_{2} \sigma^{2}}<0$. Overall, we can conclude that the inclusion of the risk-taking channel implies lower output gap and real interest rate volatility and higher inflation volatility under optimal policy.

As we did in B3.1, we can express the policy rule for the nominal interest rate as a function of expected future inflation. The parameter multiplying expected inflation could be interpreted as an optimal Taylor rule parameter $\phi_{\pi}^{c}$, describing how the central bank should react to expected inflation under commitment:

$\hat{R}_{t}=\phi_{\pi}^{c} \mathbb{E}_{t} \pi_{t+1}=\frac{\theta(\lambda \rho(1-\beta \rho)+\kappa(1-\rho) \sigma(\sigma+\varphi))+\kappa(1-\rho)^{2} \rho \mathcal{R}_{2} \sigma^{2}(1-\beta \rho)}{\rho(1-\beta \rho)\left(\theta \lambda+\kappa(1-\rho)^{2} \mathcal{R}_{2} \sigma^{2}\right)} \mathbb{E}_{t} \pi_{t+1}$

We can see that the presence of the risk-taking channel lowers the optimal response of the nominal interest rate to expected inflation, i.e.:

$\frac{\partial \phi_{\pi}^{c}}{\partial \mathcal{R}_{2}}=-\frac{\theta \kappa(\rho-1)^{3} \sigma^{3}(\sigma(\kappa+\rho-1)+\kappa \varphi)}{(\rho(\beta+\kappa)-1)\left(\theta \lambda+\kappa(\rho-1)^{2} \mathcal{R}_{2} \sigma^{2}\right)^{2}}-\frac{\theta \kappa^{2}(1-\rho)^{3} \sigma^{3}(\sigma+\varphi)}{\rho(1-\beta \rho)\left(\theta \lambda+\kappa(1-\rho)^{2} \sigma^{2}\right)^{2}}<0$ 


\section{B3.3: Fully optimal policy}

Under full commitment, the central bank's problem is to maximize (47), by choosing conditional paths for inflation, the output gap and the interest rate. The associated Lagrangian is given by

$$
\begin{aligned}
\mathcal{L}_{0}=-\frac{1}{2} \mathbb{E}_{0}\left\{\sum_{t=0}^{\infty} \beta^{t}[\right. & \left.\pi_{t}^{2}+\lambda x_{t}^{2}+\frac{\kappa}{\theta} \mathcal{R}_{2}\left(\hat{R}_{t}^{r}\right)^{2}\right] \\
& +\chi_{t}\left[x_{t}-x_{t+1}+\frac{1}{\sigma}\left(\hat{R}_{t}-\pi_{t+1}\right)\right] \\
& +\psi_{t}\left[\pi_{t}-\beta \pi_{t+1}-\kappa(\sigma+\varphi) x_{t}-u_{t}\right] \\
& \left.+\varsigma_{t}\left(-\hat{R}_{t}^{r}+\hat{R}_{t}-\pi_{t+1}\right)\right\}
\end{aligned}
$$

The multipliers associated to the Phillips curve, the IS curve and the definition of the real rate are respectively $\psi_{t}, \chi_{t}$ and $\varsigma_{t}$. The FOCs wrt. $\pi_{t}, x_{t}, \hat{R}_{t}, \hat{R}_{t}^{r}, \varsigma_{t}$ are:

$$
\begin{aligned}
\pi_{t}+\psi_{t}-\psi_{t-1}-\frac{1}{\sigma \beta} \chi_{t-1}-\frac{1}{\beta} \varsigma_{t-1} & =0 \\
\lambda x_{t}-\kappa(\sigma+\varphi) \psi_{t}+\chi_{t}-\frac{1}{\beta} \chi_{t-1} & =0 \\
\frac{1}{\sigma} \chi_{t}+\varsigma_{t} & =0 \\
\frac{\kappa}{\theta} \mathcal{R}_{2} \hat{R}_{t}^{r}-\varsigma_{t} & =0 \\
x_{t}-x_{t+1}+\frac{1}{\sigma}\left(\hat{R}_{t}-\pi_{t+1}\right) & =0 \\
\pi_{t}-\beta \pi_{t+1}-\kappa(\sigma+\varphi) x_{t}-u_{t} & =0 \\
-\hat{R}_{t}^{r}+\hat{R}_{t}-\pi_{t+1} & =0
\end{aligned}
$$


with $\chi_{-1}=\psi_{-1}=0$. We can eliminate $\hat{R}_{t}^{r}$ and $\varsigma_{t}$ to simplify the system somewhat

$$
\begin{aligned}
\pi_{t}+\psi_{t}-\psi_{t-1}-\frac{1}{\sigma \beta} \chi_{t-1}-\frac{\kappa}{\beta \theta} \mathcal{R}_{2}\left(\hat{R}_{t-1}-\pi_{t}\right) & =0 \\
\lambda x_{t}-\kappa(\sigma+\varphi) \psi_{t}+\chi_{t}-\frac{1}{\beta} \chi_{t-1} & =0 \\
\frac{1}{\sigma} \chi_{t}+\frac{\kappa}{\theta} \mathcal{R}_{2}\left(\hat{R}_{t}-\pi_{t+1}\right) & =0 \\
x_{t}-x_{t+1}+\frac{1}{\sigma}\left(\hat{R}_{t}-\pi_{t+1}\right) & =0 \\
\pi_{t}-\beta \pi_{t+1}-\kappa(\sigma+\varphi) x_{t}-u_{t} & =0
\end{aligned}
$$

Unfortunately, no simple analytical solution is available for the rational expectations equilibrium defined by these conditions.

However, it is possible to combine the first three equations to derive the following implicit instrument rule as in Giannoni and Woodford (2003). This rule applies from $t \geq 2$ and is optimal from a timeless perspective:

$$
\hat{R}_{t}=\rho_{1} \hat{R}_{t-1}+\rho_{2} \Delta \hat{R}_{t-1}+\phi_{E \pi} \mathbb{E}_{t} \pi_{t+1}+\phi_{\pi} \pi_{t}+\phi_{\pi_{-1}} \pi_{t .-1}+\phi_{x} \Delta x_{t}
$$

where

$$
\begin{aligned}
\rho_{1} & =1 \\
\rho_{2} & =\frac{1}{\beta} \\
\phi_{E \pi} & =1 \\
\phi_{\pi} & =\frac{\theta \sigma+\theta \varphi}{\mathcal{R}_{2} \sigma}-\frac{1}{\beta}-1 \\
\phi_{\pi-1} & =\frac{1}{\beta} \\
\phi_{x} & =\frac{\theta \lambda}{\mathcal{R}_{2} \kappa \sigma}
\end{aligned}
$$

As in Giannoni and Woodford (2003), this Taylor-type rule exhibits a nontrivial degree of persistence: $\rho_{1}=1, \rho_{2} \gg 0$. By construction, the optimal Taylor rule under no commitment or under optimal simple rules does not feature any persistence. As Woodford (2003) shows, in the standard NKM - i.e. in this model without the risk-taking channel - the fully optimal interest rate paths do not involve any explicit 
reference to the path of interest rates either. ${ }^{31}$ Thus, under fully optimal policy the risk-taking channel requires persistent policy responses. This is a result of the fact that the interest rate appears in the welfare function.

The risk-taking channel thus provides an additional explanation for interest rate inertia, which is routinely built into Taylor rules in models and which is typically observed in practice. Our theory augments other theories such as the zero lower bound or the cost of holding money, which regularly motivate researchers to include the interest rate - the nominal one, not the real one as in our case - in the welfare function and which also lead to inertia under optimal policy.

\footnotetext{
${ }^{31}$ Note that the above rule does not nest a rule for the standard NKM. However, as the weight on real rate stabilization $\frac{\kappa}{\theta} \mathcal{R}_{2}^{2}$ approaches 0 , past interest rates become less important in the determination of the current interest rate relative to deviations in output and inflation.
} 


\section{Appendix C: Additional figures}

Figure 2: Risk taking in the model and in the data: The figure compares the value of loan safety $q_{t}$ implied by the estimated model (in particular we plot the mean of the series posterior distribution) with a survey-based index of loan safety computed from the US Terms of Business Lending Survey. The figure is borrowed from Abbate and Thaler (2019). See this paper for more details on the estimation procedure and the empirical risk measure.

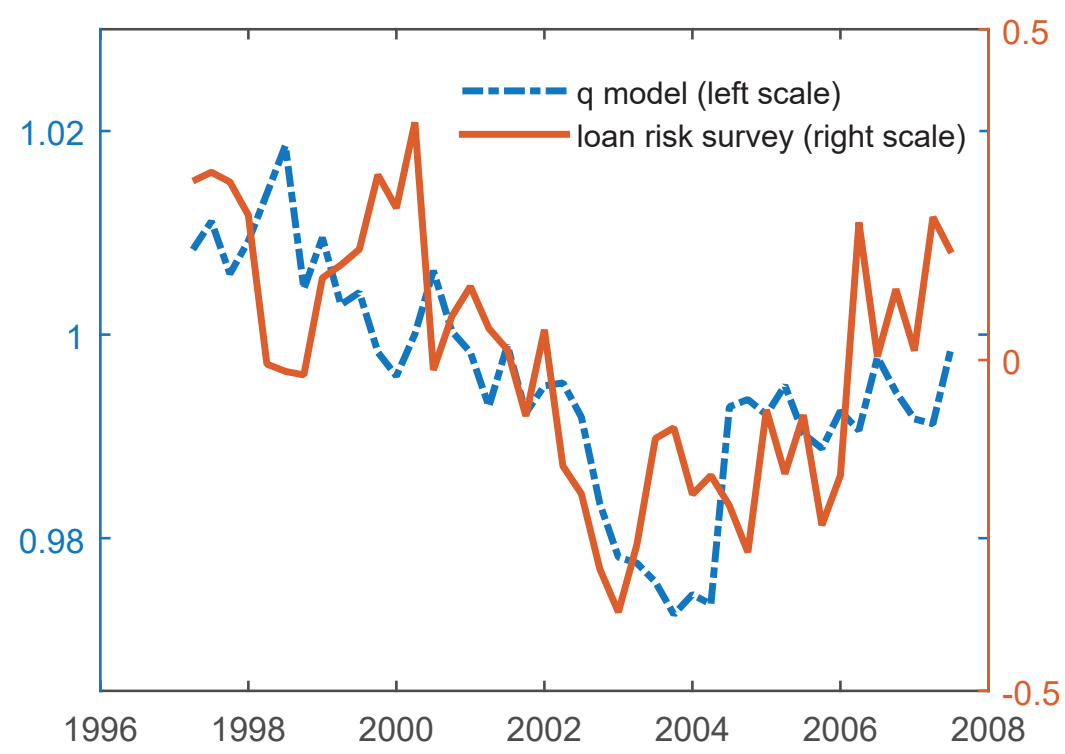


2021-09 Angela Abbate, Dominik Thaler: Optimal monetary policy with the risk-taking channel

2021-08 Thomas Nitschka, Shajivan Satkurunathan: Habits die hard: implications for bond and stock markets internationally

2021-07 Lucas Fuhrer, Nils Herger: Real interest rates and demographic developments across generations: A panel-data analysis over two centuries

2021-06 Winfried Koeniger, Benedikt Lennartz, Marc-Antoine Ramelet: On the transmission of monetary policy to the housing market

2021-05 Romain Baeriswyl, Lucas Fuhrer, Petra Gerlach-Kristen, Jörn Tenhofen:

The dynamics of bank rates in a negative-rate environment - the Swiss case

2021-04 Robert Oleschak:

Financial inclusion, technology and their impacts on monetary and fiscal policy: theory and evidence

2021-03 David Chaum, Christian Grothoff, Thomas Moser: How to issue a central bank digital currency

2021-02 Jens H.E. Christensen, Nikola Mirkov: The safety premium of safe assets

2021-01 Till Ebner, Thomas Nellen, Jörn Tenhofen: The rise of digital watchers

2020-25 Lucas Marc Fuhrer, Marc-Antoine Ramelet, Jörn Tenhofen: Firms' participation in the COVID-19 loan programme

2020-24 Basil Guggenheim, Sébastien Kraenzlin, Christoph Meyer:

(In)Efficiencies of current financial market infrastructures - a call for DLT?
2020-23 Miriam Koomen, Laurence Wicht:

Demographics, pension systems, and the current account: an empirical assessment using the IMF current account model

2020-22 Yannic Stucki, Jacqueline Thomet: A neoclassical perspective on Switzerland's 1990s stagnation

2020-21 Fabian Fink, Lukas Frei, Oliver Gloede: Short-term determinants of bilateral exchange rates: A decomposition model for the Swiss franc

2020-20 Laurence Wicht:

A multi-sector analysis of Switzerland's gains from trade

2020-19 Terhi Jokipii, Reto Nyffeler, Stéphane Riederer: Exploring BIS credit-to-GDP gap critiques: the Swiss case

2020-18 Enzo Rossi, Vincent Wolff: Spillovers to exchange rates from monetary and macroeconomic communications events

2020-17 In Do Hwang, Thomas Lustenberger, Enzo Rossi: Does communication influence executives' opinion of central bank policy?

2020-16 Peter Kugler, Samuel Reynard:

Money, inflation and the financial crisis: the case of Switzerland

2020-15 Sébastien Kraenzlin, Christoph Meyer, Thomas Nellen: COVID-19 and regional shifts in Swiss retail payments

2020-14 Christian Grisse:

Lower bound uncertainty and long-term interest rates 
